\title{
Parkin Modulates Endosomal Organization and Function of the Endo-Lysosomal Pathway
}

\author{
Pingping Song, Katarina Trajkovic, Taiji Tsunemi, and Dimitri Krainc \\ Department of Neurology, Northwestern University Feinberg School of Medicine, Chicago, Illinois 60611
}

Mutations in PARK2 (parkin), which encodes Parkin protein, an E3 ubiquitin ligase, are associated with autosomal recessive early-onset Parkinson's disease (PD). While several studies implicated Parkin in the regulation of mitophagy and proteasomal degradation, the precise mechanism leading to neurodegeneration upon Parkin loss of function remains incompletely understood. In this study, we found that Parkin modulates the endocytic pathway through the regulation of endosomal structure and function. We showed that loss of Parkin function led to decreased endosomal tubulation and membrane association of vesicle protein sorting 35 (VPS35) and sorting nexin 1 (SNX1), as well as decreased mannose 6 phosphate receptor (M6PR), suggesting the impairment of retromer pathway in Parkin-deficient cells. We also found increased formation of intraluminal vesicles coupled with enhanced release of exosomes in the presence of mutant Parkin. To elucidate the molecular mechanism of these alterations in the endocytic pathway in Parkin-deficient cells, we found that Parkin regulates the levels and activity of Rab7 by promoting its ubiquitination on lysine 38 residue. Both endogenous Rab7 in Parkin-deficient cells and overexpressed K38 R-Rab7 mutant displayed decreased effector binding and membrane association. Furthermore, overexpression of K38R-Rab7 in HEK293 cells phenocopied the increased secretion of exosomes observed in Parkin-deficient cells, suggesting that Rab7 deregulation may be at least partially responsible for the endocytic phenotype observed in Parkin-deficient cells. These findings establish a role for Parkin in regulating the endo-lysosomal pathway and retromer function and raise the possibility that alterations in these pathways contribute to the development of pathology in Parkin-linked Parkinson's disease.

Key words: Parkin; Parkinson's disease; retromer; tubulation; multivesicular endosome; exosome

Significance Statement

Our work highlights the importance of Parkin in controlling the endocytic pathway by regulation of retromer function, endosomal tubulation, and inward vesiculation, and the secretion of exosomes.

\section{Introduction}

Parkinson's disease (PD) affects $1 \%-2 \%$ of the population and is the second most common neurodegenerative disease characterized by resting tremor, rigidity, and bradykinesia. The motor defects of PD are largely due to the progressive loss of dopaminergic (DA) neurons in the substantia nigra pars compacta $(\mathrm{SNc})$, and to a lesser extent the ventral tegmental area (VTA) and other midbrain regions. (Spillantini et al., 1997; Klein and Krainc, 2012; Hunn et al., 2015; Pickrell and Youle, 2015). Although most

\footnotetext{
Received July 6, 2015; revised Jan. 12, 2016; accepted Jan. 18, 2016.

Author contributions: P.S., K.T., and D.K. designed research; P.S. and T.T. performed research; P.S., K.T., and D.K. analyzed data; P.S., K.T., and D.K. wrote the paper.

This work was supported by NINDS Grant R01NS076054 to D.K. We thank Prof. Jianbin Zheng for providing reagent ( $p$-xylene-bis-pyridinium bromide); Dr. Kana Hamada for technical assistance; Prof. Jean Gruenberg (University of Geneva, Switzerland) for providing Venus-SNX16 plasmid; and Dr. Christine Klein for providing Parkin patient fibroblasts.

The authors declare no competing financial interests.

Correspondence should be addressed to Dr. Dimitri Krainc, Northwestern University Feinberg School of Medicine, 303 E. Chicago Avenue, Ward 12-140, Chicago, IL 60611. E-mail: krainc@northwestern.edu.

DOI:10.1523/JNEUROSCI.2569-15.2016

Copyright $\odot 2016$ the authors $\quad 0270-6474 / 16 / 362425-13 \$ 15.00 / 0$
}

PD patients develop a late-onset disease with no obvious genetic cause, a subset of affected individuals develop early-onset or familial forms associated with various genetic mutations. Studies of the effects of these mutations have provided valuable insights into the pathways and mechanisms ultimately leading to degeneration of dopaminergic neurons (Cookson, 2009; Yasuda et al., 2013). Mutations in parkin lead to autosomal recessive early-onset PD (Hunn et al., 2015). Parkin is a multifunctional E3 ubiquitin (UB) ligase implicated in several cellular processes through ubiquitination of its substrates. For instance, Parkin-mediated ubiquitination of mitochondrial proteins (Gegg et al., 2010; Geisler et al., 2010; Poole et al., 2010; Sarraf et al., 2013) triggers degradation of dysfunctional mitochondria through the autophagylysosome pathway (Narendra et al., 2008), although it remains controversial whether endogenous Parkin can induce mitophagy (Imaizumi et al., 2012; Rakovic et al., 2013). Recently, genetic studies showed that overexpression of VPS35, a subunit of the retromer complex, was able to rescue parkin mutant phenotypes in Drosophila, suggesting that Parkin functions in the same pathway as VPS35 (Malik et al., 2015). Interestingly, one study dem- 
onstrated that Parkin mediates the ubiquitination of Epidermal Growth Factor Receptor (EGFR) Pathway Substrate 15 (Eps15), an adaptor protein involved in early endocytosis (Fallon et al., 2006), suggesting a possible role of Parkin in the endo-lysosomal pathway.

The endo-lysosomal pathway has multiple roles in cell maintenance. It enables internalization of extracellular fluids along with the portions of the plasma membrane, as well as sorting of the internalized membrane and its protein constituents. The main sorting stations along the pathway are early and late endosomes, dynamic, pleiomorphic organelles with tubulo-cisternal and multivesicular domains, the latter filled with intraluminal vesicles (ILVs) (Gruenberg, 2001). Endosomal cargo can be delivered to lysosomes where degradation occurs, recycled back to the plasma membrane via recycling endosomes, or transported to the Golgi apparatus via the retromer pathway (Scott et al., 2014). Some endosomes fuse with the plasma membrane, thereby discharging into the extracellular environment their ILVs, which then become exosomes (Kowal et al., 2014). The dynamics of sorting, transport, and membrane remodeling in the endocytic pathway is controlled by a complex regulatory machinery, which includes Rab GTPases, the major regulators of vesicular trafficking (Numrich and Ungermann, 2014).

In this study, we found that Parkin regulates the endolysosomal pathway, in particular the organization of the tubular and multivesicular regions, which further affect the retromer pathway and exosome secretion. Furthermore, Parkin ubiquitinates late-endosomal GTPase Rab7, thereby regulating its activity and stability. Together, our data reveal a novel function of Parkin in modulating the endo-lysosomal pathway through the regulation of retromer function and endosomal organization, and raise the possibility that the disruption of this pathway contributes to the pathogenesis of Parkin-linked PD.

\section{Materials and Methods}

Cell culture and transfections. HEK293 cells were cultured in $10 \mathrm{~cm}$ dishes and grown at $37^{\circ} \mathrm{C}$ in $5 \% \mathrm{CO}_{2}$ in full medium: DMEM (Invitrogen) containing 10\% FBS (Invitrogen). For transfections, we used Lipofectamine 2000 (Invitrogen) transfection system. Primary dermal fibroblasts from $\mathrm{PD}$ patients carrying a homozygous mutation in parkin gene, MUT1 (B125: c.1072Tdel, male, age at onset 43) and MUT2 (B300: delEx7, female, age at onset 34), and healthy controls CON1 (male) and CON2 (male) were cultured in fibroblast medium: DMEM supplemented with 15\% FBS (Invitrogen), and L-glutamine (Invitrogen), and the media was changed every $2 \mathrm{~d}$. Cells were subcultured at a ratio of 1:2 or 1:3. For transfections, we used Neon Transfection System (Invitrogen) according to the manufacturer's specifications.

Human-induced pluripotent stem (iPS) cells derived from parkin mutant (B125 and B300) and two healthy control [CON1 (male) and CON2 (male)] fibroblasts were maintained on irradiated MEF (Global Stem) feeder layers in iPS cell media: DMEM/F12 (Stem Cell Technologies) with $20 \%$ knock-out serum replacement (Invitrogen), L-glutamine, nonessential amino acids, 2-mercaptoethanol (Invitrogen), $10 \mathrm{ng} / \mathrm{ml}$ FGF-Basic (AA1-155) recombinant human protein (Invitrogen), and penicillin/streptomycin at $37^{\circ} \mathrm{C}$ in $5 \% \mathrm{CO}_{2}$. iPS cell colonies were passaged by chunking manually. Directed differentiation toward DA neurons was conducted as described previously (Chambers et al., 2009; Kriks et al., 2011; Mazzulli et al., 2011) with minor modifications. Briefly, undifferentiated iPS cell colonies were dissociated into single cells using Accutase (Sigma) and replated onto Matrigel-coated (BD Bioscience) dishes in iPS cell media precultured with MEF cells for $24 \mathrm{~h}$. Differentiation was started at a confluence of $100 \%$ by adding knock-out serum replacement medium (Invitrogen) containing Noggin (R\&D Systems) and SB431542 (Tocris Bioscience). On day 13, cells were passaged and plated onto $10 \mathrm{~cm}$ dishes precoated with poly-D-lysine (Sigma) and laminin (Roche). Differentiation into DA neurons was conducted by adding brain-derived neurotrophic factor (R\&D Systems), ascorbic acid (Sigma), recombinant human sonic hedgehog (R\&D Systems), and recombinant human FGF-8a (R\&D Systems).

Western blot analysis. Cells were scrapped from 12 or 6 well plates in cold PBS and centrifuged at $300 \times g$ for $5 \mathrm{~min}$. Pellets were resuspended in lysis buffer ( $50 \mathrm{~mm}$ Tris- $\mathrm{HCl}, \mathrm{pH}$ 7.5, $150 \mathrm{~mm} \mathrm{NaCl}, 1 \mathrm{~mm}$ EDTA, $1 \%$ Triton X-100, $0.1 \%$ SDS) with protease inhibitors (Roche) and incubated on ice for $30 \mathrm{~min}$ with extensively pipetting every $10 \mathrm{~min}$ followed by centrifuging at $13,500 \mathrm{rpm}$ for $10 \mathrm{~min}$ at $4^{\circ} \mathrm{C}$. Protein concentration of supernatants was measured using bicinchoninic acid assay (Sigma). Samples were analyzed by SDS-PAGE and Western blot. Antibodies used for immunoblotting included anti-HA antibody (Cell Signaling Technology), anti-Rab7 antibody (Sigma), anti-GFP antibody (Clontech), anti-Rab5 antibody (Abcom), anti-Parkin antibody (Santa Cruz Biotechnology), anti-actin antibody (Sigma), anti-GST antibody (Sigma), and anti-UB antibody (ENZO).

Recombinant protein purification. For purification of recombinant GST, GST-Rab7, or GST-K38R, Escherichia coli BL21 (NEB) bacterial cells transformed with plasmids pGEX-vector or pGEX-Rab7 were precultured overnight at $37^{\circ} \mathrm{C}$ in $2 \mathrm{ml}$ of terrific broth (TB) medium (Invitrogen) supplemented with $50 \mu \mathrm{g} / \mathrm{ml}$ carbenicillin (Sigma), and then transferred to $500 \mathrm{ml}$ of fresh medium. After incubation for $4 \mathrm{~h}$ at $37^{\circ} \mathrm{C}$ (optical density at $600 \mathrm{~nm}$ reached 0.6 ), isopropyl-b-D-thiogalactoside (IPTG) was added into the culture medium at a final concentration of 0.5 $\mathrm{mM}$, and bacteria were further cultured for protein production for $4 \mathrm{~h}$ at $30^{\circ} \mathrm{C}$. The cells were collected, suspended in B-PER reagent (Thermo Scientific) with protease inhibitors, and incubated $15 \mathrm{~min}$ at room temperature. After centrifugation at $15,000 \times g$ for $5 \mathrm{~min}$, the supernatant was purified by adding $1 \mathrm{ml}$ of preequilibrated 50\% slurry of GST beads (GE Healthcare), and incubated for $2 \mathrm{~h}$ at $4^{\circ} \mathrm{C}$. Beads were washed with PBS, and GST-Rab7 protein was eluted with elution buffer (20 mm glutathionereduced, Sigma; $100 \mathrm{~mm}$ Tris-HCl, $\mathrm{pH} 8.0$ and $120 \mathrm{~mm} \mathrm{NaCl}$ ).

For purification of GST-Parkin, HEK293 cells were transfected with pEBG-Parkin plasmid. After $48 \mathrm{~h}$, the cells were washed with PBS and harvested in lysis buffer (50 mM Tris- $\mathrm{HCl}, \mathrm{pH} 7.5,150 \mathrm{~mm} \mathrm{NaCl}, 1 \mathrm{~mm}$ EDTA, $1 \%$ Triton X-100, $0.1 \%$ SDS) with protease inhibitors, and then incubated for $30 \mathrm{~min}$ on a shaker at $4^{\circ} \mathrm{C}$. After centrifugation at 13,500 $\mathrm{rpm}$ for $10 \mathrm{~min}$ at $4^{\circ} \mathrm{C}$, the supernatant was incubated with $500 \mu \mathrm{l}$ of preequilibrated $50 \%$ slurry of GST beads for $2 \mathrm{~h}$ at $4^{\circ} \mathrm{C}$. Beads were washed with PBS, and GST-Parkin protein was eluted with elution buffer. Fractions containing purified protein were concentrated using 10 $\mathrm{kDa}$ concentrators (Millipore).

For in vitro protein synthesis of UB S65D, we used TNT quick-coupled transcription/translation system (Promega) according to the manufacturer's instructions. Briefly, pCMV-TNT-UB S65D plasmid was incubated with TNT Quick Master Mix at $30^{\circ} \mathrm{C}$ for $90 \mathrm{~min}$. Then, the reaction was stopped by freeze-thawing twice. Translated UB S65D protein was analyzed by Western blot.

In vitro ubiquitination assay. Ubiquitination reactions were performed at $25^{\circ} \mathrm{C}$ in $50 \mathrm{~mm}$ Tris- $\mathrm{HCl}$, $\mathrm{pH} 7.5,5 \mathrm{~mm} \mathrm{MgCl}_{2}, 2$ mм DTT, $2 \mathrm{~mm} \mathrm{ATP,}$ $100 \mathrm{ng}$ E1 and $200 \mathrm{ng}$ E2 (UbcH7) buffer system; $2 \mu \mathrm{g}$ GST or GSTParkin protein was incubated with $2 \mu \mathrm{g}$ GST-Rab7a protein in the presence or absence of UB S65D protein in $50 \mu \mathrm{l}$ final reaction volume for $2 \mathrm{~h}$.

Immunoprecipitation. Cells were harvested from $6 \mathrm{~cm}$ dishes in icecold PBS and centrifuged at $300 \times g$ for $5 \mathrm{~min}$. Pellets were resuspended in lysis buffer (50 mM Tris- $\mathrm{HCl}, \mathrm{pH}$ 7.5, $150 \mathrm{~mm} \mathrm{NaCl}, 1$ mм EDTA, 1\% NP40, $10 \%$ glycerol) with protease inhibitors and incubated on ice for 30 min followed by centrifugation at $13,500 \mathrm{rpm}$ for $10 \mathrm{~min}$ at $4^{\circ} \mathrm{C} ; 500 \mu \mathrm{g}$ of protein lysate was incubated with $1 \mu \mathrm{l}$ anti-HA (Sigma) or anti-Rab7 (Proteintech) antibody overnight at $4{ }^{\circ} \mathrm{C}$ with rotation, followed by incubation with $30 \mu \mathrm{l}$ protein $\mathrm{G}$ beads for another $2 \mathrm{~h}$. Beads were collected by centrifugation at $200 \times g$ for 2 min and washed three times with lysis buffer. Proteins were eluted by boiling in $2 \times$ Laemmli buffer.

GST-RILP pull-down assay. GST-RILP pull-down assay was performed as described previously (Romero Rosales et al., 2009), with minor modifications as follows: bacterial cells transformed with GST-RILP were pelleted, washed with cold PBS, resuspended in B-PER with protease inhibitors, and incubated $10-15 \mathrm{~min}$ at room temperature. Cell 
lysates were cleared by centrifugation at $15,000 \times g$ for $5 \mathrm{~min}$. GST-RILP was purified by incubation with $300 \mu$ l of preequilibrated $50 \%$ slurry of GST beads for $1 \mathrm{~h}$ at $4^{\circ} \mathrm{C}$. Beads were washed with B-PER, resuspended to a $50 \%$ slurry, and kept at $4^{\circ} \mathrm{C}$.

EGFR degradation assay. Parkin-deficient and control fibroblasts were serum-starved for $16 \mathrm{~h}$ and treated with $10 \mu \mathrm{g} / \mathrm{ml}$ of cycloheximide (EMD Millipore; Calbiochem) for $1 \mathrm{~h}$ to block new protein synthesis. Cells were incubated with $100 \mathrm{ng} / \mathrm{ml}$ epidermal growth factor (Peprotech) for the indicated time points.

Immunofluorescence. Parkin-deficient and control fibroblasts were washed with PBS, fixed with fresh 3\% formaldehyde in PBS for 20 min at room temperature, and preincubated in blocking buffer $(0.1 \%$ saponin and $10 \%$ FBS in PBS) for $1 \mathrm{~h}$ at room temperature. The specimens were incubated with the primary antibodies against CD63 (DSHB), lysosomal-associated membrane protein 1 (LAMP1) (Santa Cruz Biotechnology), or early endosomal entigen 1 (EEA1) (BD Transduction Laboratories) in blocking buffer for $1 \mathrm{~h}$ at room temperature, then washed with PBS and incubated with Alexa-488-conjugated goat antimouse antibody (Invitrogen) or Alexa-568-conjugated goat anti-rabbit antibody (Invitrogen) for $1 \mathrm{~h}$ at room temperature. After washing with PBS, the specimens were mounted in the mounting medium with $4^{\prime}$,6diamidino-2-phenylindole (DAPI; Vector Laboratories).

Live cell imaging. Parkin-deficient and control fibroblasts were cultured in glass bottom $35 \mathrm{~cm}$ dishes and transfected with Venus-SNX16 plasmid. Twelve hours later, images of Venus-sorting nexin 16 (SNX16) motility were acquired on Andor Spinning Disk Confocal Microscope with a $63 \times$ oil-immersion objective in a temperature-controlled chamber $\left(37^{\circ} \mathrm{C}\right)$. Digital images were acquired at 1 frame every $7 \mathrm{~s}$ for 60 frames and played back at $49 \times$.

Electron microscopy. Transmission electron microscopy was used to examine the ultrastructure of multivesicular bodies (Tsunemi et al., 2014). Briefly, fibroblasts were fixed with $2.5 \%$ glutaraldehyde in PBS, followed by $1 \%$ osmium tetroxide for $1 \mathrm{~h}$. After dehydrated and stained with $1 \%$ uranyl acetate, the specimens were embedded in LX112 resin (Ladd). The resin blocks were sectioned with a thickness of $70 \mathrm{~nm}$. At least 50 vesicles from 10 different cells in each cell lines were observed under FEI Tecnai Spirit G2 transmission electron microscope.

Cell fractionation assay. Cell fractionation was performed as described previously (Seaman et al., 2009). Briefly, cells grown in $10 \mathrm{~cm}$ dishes were washed with PBS, snap frozen using liquid nitrogen, and then thawed on the bench. Cells were scraped in $0.5 \mathrm{ml}$ of buffer $(0.1 \mathrm{M} \mathrm{Mes}-\mathrm{NaOH}, \mathrm{pH}$ 6.5, $1 \mathrm{~mm}$ magnesium acetate, $0.5 \mathrm{~mm}$ EGTA, $200 \mu \mathrm{m}$ sodium orthovanadate and $0.2 \mathrm{M}$ sucrose), and the lysate was centrifuged for $10 \mathrm{~min}$ at $10,000 \times g$. Cytosol-containing supernatants were aspirated and preserved, and the pellets were solubilized in $0.5 \mathrm{ml}$ of lysis buffer $(50 \mathrm{~mm}$ Tris-HCl, pH 7.4, 150 mм NaCl, 1 mм EDTA, 1\% Triton X-100, 0.1\% SDS) and recentrifuged for $10 \mathrm{~min}$ at $10,000 \times g$. The supernatant from the second spin now contained membrane and membrane-associated proteins. Equal volumes of the first (cytosol) and the second (membrane) supernatants were subjected to SDS-PAGE and Western blot.

In vitro invagination assay. In vitro invagination assay was performed as described previously (Falguières et al., 2008). Briefly, cells were grown in $10 \mathrm{~cm}$ dishes, washed with cold PBS, and scraped with a rubber policeman in PBS, followed by centrifugation at $150 \times g$ for $5 \mathrm{~min}$ at $4^{\circ} \mathrm{C}$. Pellets were washed with $8.5 \%$ sucrose, centrifuged at $750 \times g$ for $10 \mathrm{~min}$ at $4^{\circ} \mathrm{C}$, resuspended in $8.5 \%$ sucrose with protease inhibitors, and homogenized by passing 4 times through a G22 needle, followed by centrifugation at $750 \times \mathrm{g}$ for $10 \mathrm{~min}$ at $4^{\circ} \mathrm{C}$. Postnuclear supernatants (PNSs) were collected, and protein concentration was determined using Bradford protein assay. PNSs were incubated with $1 \mathrm{~mm}$ HPTS (the nonpermeant fluorophore 8-hydroxypyrene-1,3,6-trisulfonic acid), salts (12.5 mM HEPES, pH 7.0, $1.5 \mathrm{~mm} \mathrm{MgOAc}_{2}$, and $1 \mathrm{~mm} \mathrm{DTT),} 100 \mathrm{~mm} \mathrm{KCl}$ and ATP regeneration cassette ( $2 \mathrm{~mm}$ ATP, $0.08 \mathrm{mg} / \mathrm{ml}$ creatine kinase, and $16 \mathrm{~mm}$ creatine phosphate) at $37^{\circ} \mathrm{C}$ for $20 \mathrm{~min}$. Finally, uninternalized HPTS was quenched by $50 \mathrm{~mm}$ p-xylene-bis-pyridinium bromide in $\mathrm{HEPES} / \mathrm{NaCl}, \mathrm{pH}$ 7.4. Light membranes were obtained by flotation in sucrose step gradients. Fluorescence was measured with Sprectromax i3.

Exosome isolation. Exosome isolation was performed as described previously (Tsunemi et al., 2014), with minor modifications as follows: exosomes were purified from cell-conditioned media by differential centrifugation method $(300 \times g$ for $10 \mathrm{~min}, 16,500 \times g$ for $20 \mathrm{~min})$, followed by ultracentrifugation at $110,000 \times g$ for $70 \mathrm{~min}$. After washing in PBS, the exosomes were collected by a centrifugation at $110,000 \times g$ for $60 \mathrm{~min}$.

Nanoparticle tracking analysis. Analyses of vesicles present in the medium were conducted as described previously (Tsunemi et al., 2014). Briefly, exosomes were measured by nanoparticle tracking system, using the NanoSight LM10 system, configured with a $405 \mathrm{~nm}$ laser and a highsensitivity digital camera system (OrcaFlash2.8, Hamamatsu C11440, NanoSight). Videos were recorded and analyzed using the NTA software (version 2.3). Samples were administered and recorded under controlled flow, using the NanoSight syringe pump and script control system.

Statistical analysis. All data were prepared for analysis with software Microsoft Excel. Statistical analysis was performed by Student's $t$ test. All error bars in figures indicate SEM.

\section{Results \\ Parkin regulates endosomal tubulation and retromer function}

A previous study demonstrated that Parkin mediated ubiquitination of Eps15, an adaptor protein involved in early endocytosis (Fallon et al., 2006), suggesting a role for Parkin in the endocytic pathway. To examine in more detail the endolysosomal pathway in the presence of mutant Parkin, we first assessed the morphology and distribution of several early and late endosomal markers in patient-derived Parkin-deficient fibroblasts. Although we did not observe significant differences in the pattern of EEA1 and LAPMP1 in Parkin-deficient cells (Fig. $1 A, B$ ), a more detailed inspection of the specific endosomal membrane regions revealed a significant loss of tubular elements labeled by SNX16, a PX domain-containing sorting nexin specifically enriched on late endosomal tubules and cisterns (Brankatschk et al., 2011) (Fig. 1C). To further confirm this observation, we conducted live cell confocal images and found a dramatic decrease in endosomal tubulation in Parkin-deficient fibroblasts (Movie 2) compared with controls (Movie 1), suggesting that Parkin is involved in endosomal membrane tubulation. We also observed a decrease in the levels of the late endosomal marker M6PR, which is a main cargo of retromer (Arighi et al., 2004) (Fig. 1D), indicative of the impairment of the retromer function. To get more insight in the retromer status, we analyzed membrane association of the retromer proteins SNX1 and VPS35 using cell fractionation assay (Seaman et al., 2009). The results showed a decreased ratio of membrane-associated and cytosolic SNX1 and VPS35 in Parkin-deficient cells compared with controls (Fig. 1E), further corroborating altered retromer function in Parkin-deficient cells.

\section{Parkin regulates ILV formation and secretion of exosomes}

Further assessment of endosomal morphology revealed dramatic accumulation of CD63, a specific marker of late endosomal multivesicular regions (Kobayashi et al., 2000) in Parkin-deficient cells compared with controls (Fig. 2A). To confirm this observation, we performed ultrastructural analysis of multivesicular bodies (MVBs) by transmission electron microscopy. We found an increased number of ILVs within MVBs in Parkin-deficient fibroblasts (Fig. $2 B$ ), corroborating the immunofluorescence results. As ILVs are formed through inward vesiculation of the endosomal limiting membrane and degraded upon endosomal fusion with lysosomes, increased number of ILVs might result from impaired degradation in lysosomes, enhanced ILV formation, or both. To evaluate the degradation efficiency in the endo- 
A

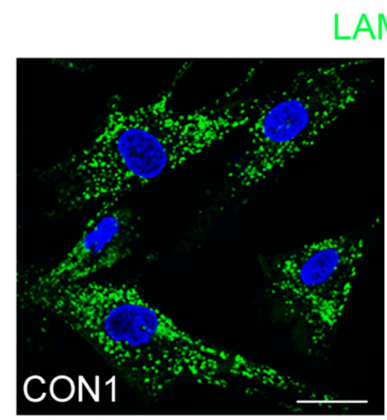

LAMP1/DAPI

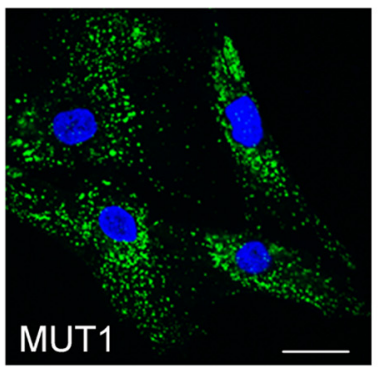

B

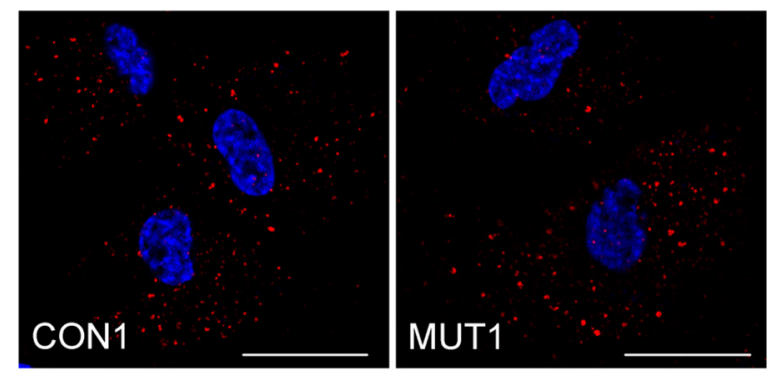

C
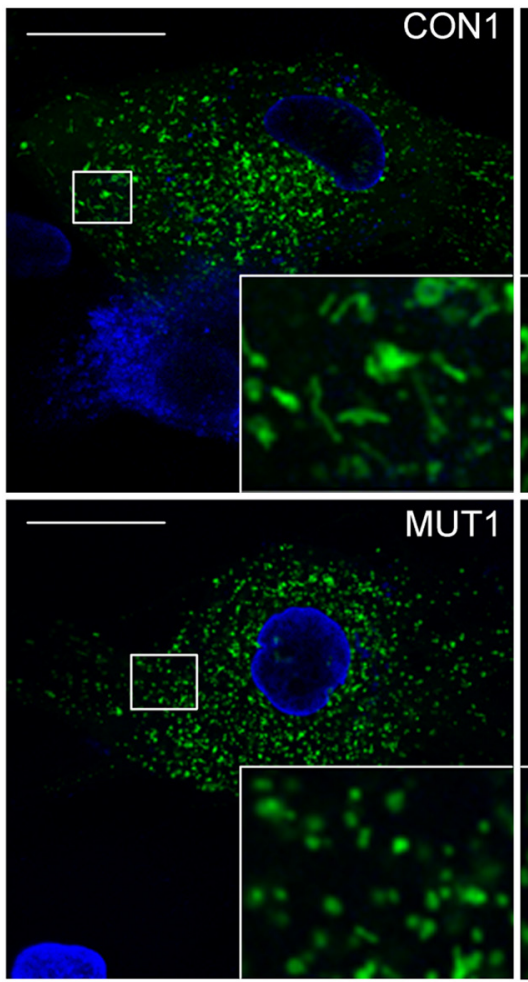
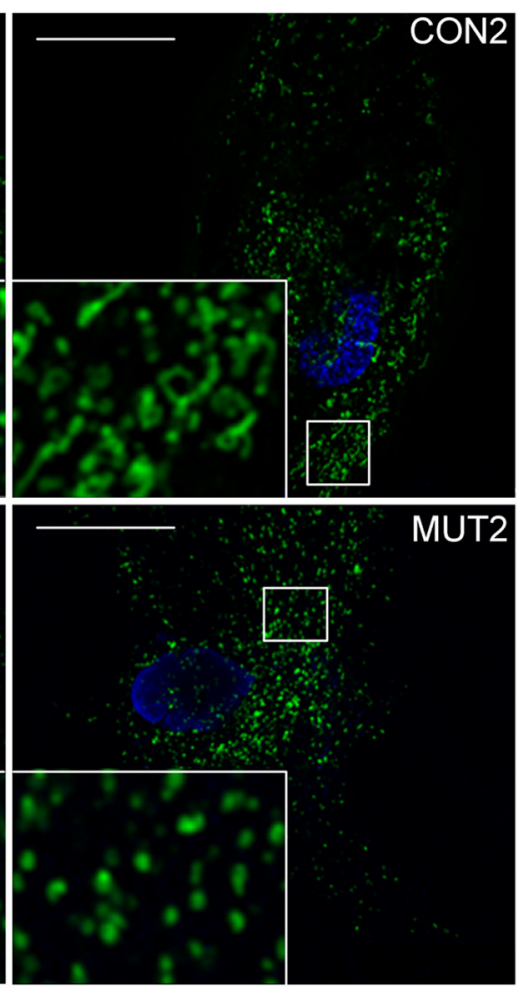

D

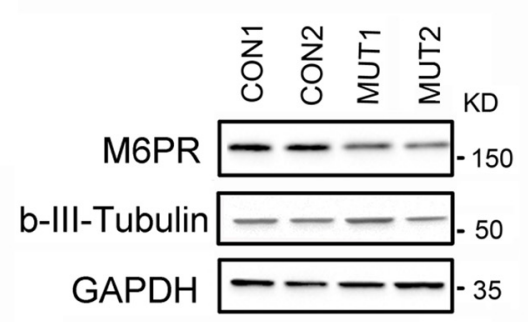

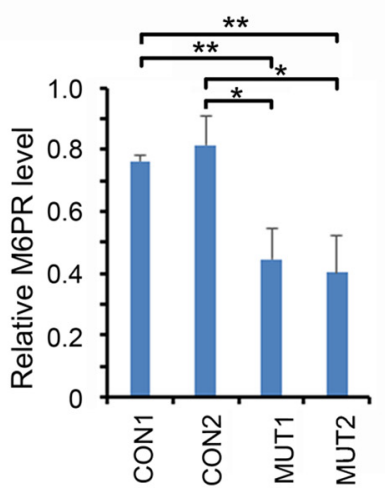

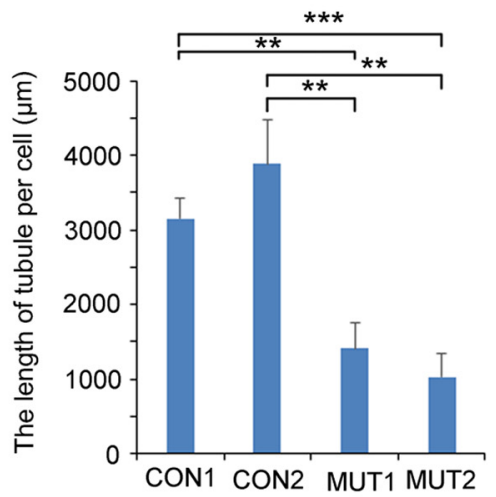

E
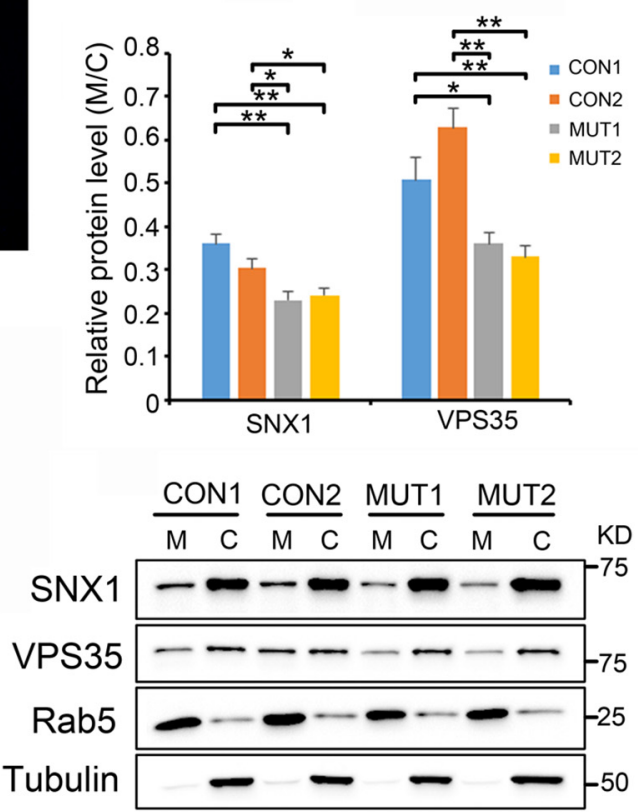

Figure 1. Decreased endosomal tubulation and impaired retromer function in Parkin-deficient cells. Immunostaining analysis of LAMP1 (green) ( $\boldsymbol{A}$ ) or EEA1 (red) ( $\boldsymbol{B})$ in Parkin-deficient (MUT1) or control (CON1) fibroblasts. Blue represents DAPI. Scale bar, $25 \mu \mathrm{m}$. C, Left, Confocal images of Venus-SNX16 (green) labeled tubules. Parkin-deficient fibroblasts MUT1 and MUT2 or controls CON1 and CON2 were transfected with Venus-SNX16 for $12 \mathrm{~h}$. Blue represents DAPI. Scale bar, $25 \mu \mathrm{m}$. Right, Total length of tubules per cell was quantified from experiments described above ( $N=3$ independent experiments). ${ }^{* *} p<0.01$. ${ }^{* * *} p<0.005$. D, Left, Western blot analysis of M6PR, b-III-Tubulin in Parkin-deficient (MUT1 and MUT2) or control (CON1 and CON2) DA neurons. Glyceraldehyde-3-phosphate dehydrogenase (GAPDH) was used as a loading control. Right, Quantification of the protein levels. M6PR levels were normalized to GAPDH ( $N=3$ independent experiments). ${ }^{*} p<0.05 . E$, Top, The ratio of membrane-associated/cytosolic proteins. Membrane-associated VPS35 or SNX1 was normalized with Rab5, and cytosolic VPS35 or SNX1 was normalized with tubulin ( $N=3$ independent experiments). ${ }^{*} p<0.05 .{ }^{* *} p<0.01$. Bottom, Western blot analysis of membrane-associated (M) or cytosolic (C) VPS35 and SNX1 in Parkin-deficient fibroblasts (MUT1 and MUT2) or control (CON1 and CON2) fibroblasts. Tubulin and Rab5 were used as loading controls. 


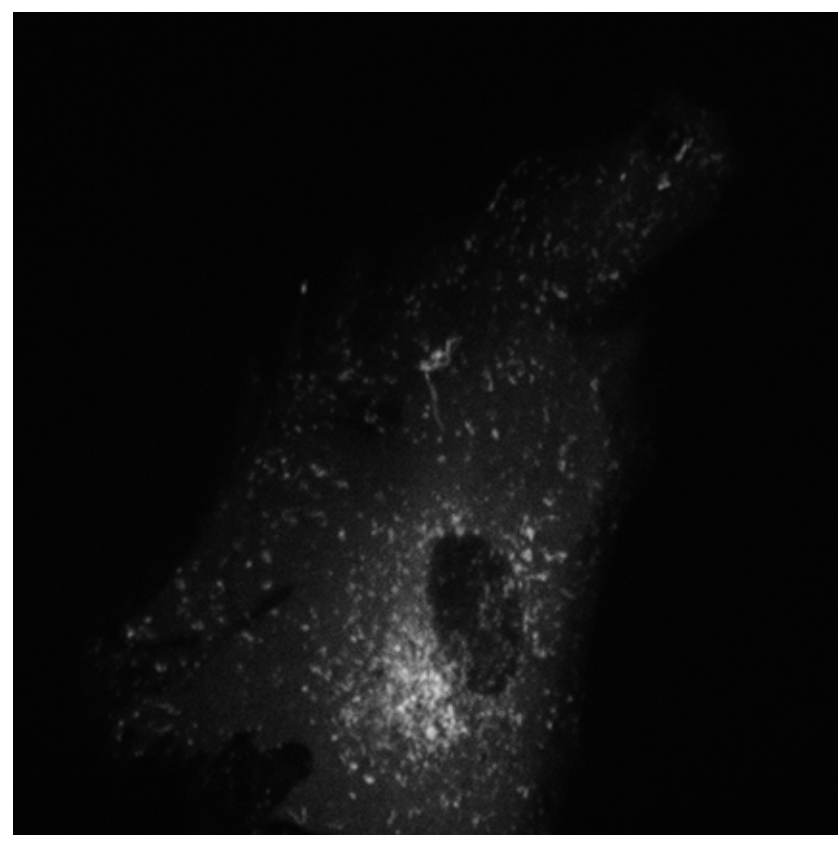

Movie 1. The movement of tubules in control fibroblasts. Control fibroblasts were transfected with Venus-SNX16 for $12 \mathrm{~h}$. Images of Venus-SNX16 motility were acquired on Andor Spinning Disk Confocal at 1 frame every $7 \mathrm{~s}$ for 60 frames and played back at $49 \times$.

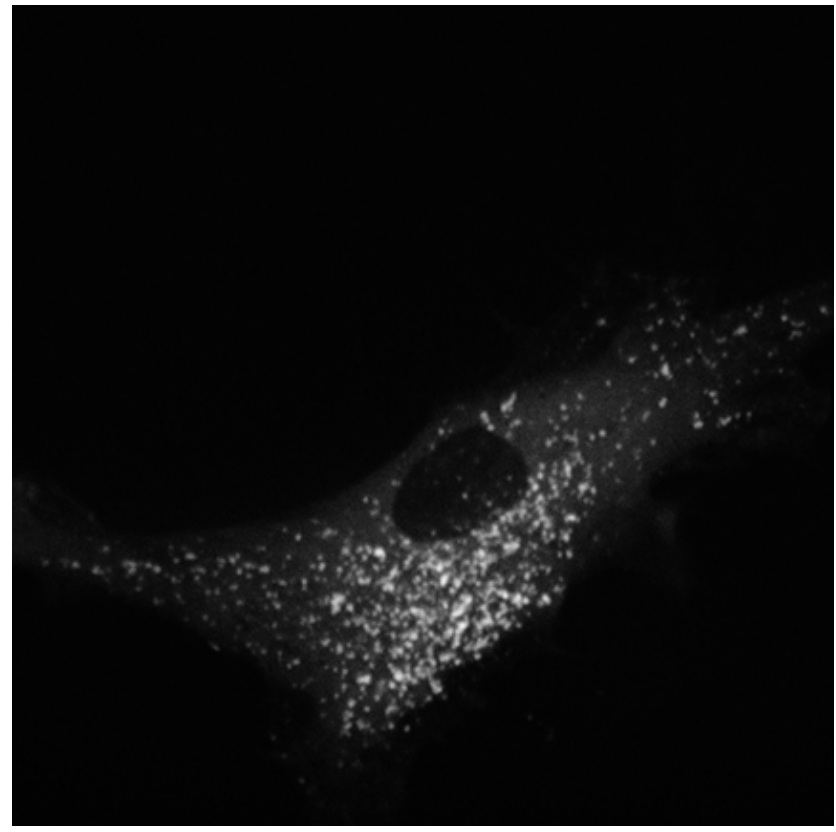

Movie 2. The movement of tubules in Parkin-deficient fibroblasts. Parkin-deficient fibroblasts were transfected with Venus-SNX16 for $12 \mathrm{~h}$. Images of Venus-SNX16 motility were acquired on Andor Spinning Disk Confocal at 1 frame every $7 \mathrm{~s}$ for 60 frames and played back at $49 \times$

lysosomal pathway, we performed EGFR degradation assay, a well-established analysis for degradative trafficking pathway, and found no significant difference between control and Parkindeficient fibroblasts (Fig. 2C). Next, we examined the ILV formation rate by an in vitro invagination assay, a quantitative biochemical assay that reconstitutes ILV formation within endosomes in vitro (Falguières et al., 2008), and found that ILV formation rate was enhanced in Parkin-deficient fibroblasts compared with control cells (Fig. 2D). Together, these results suggested that parkin mutations modulate ILV synthesis by increasing inward vesiculation of endosomes.

As ILVs formed in the multivesicular regions also act as precursors of exosomes, we hypothesized that the increased ILV formation observed in Parkin-deficient lines will lead to increased release of exosomes. To test this, we isolated exosomes from the cell culture media of Parkin-deficient or control fibroblasts by conventional centrifugation and measured the number of exosomes by nanoparticle tracking analysis (Dragovic et al., 2011; Tsunemi et al., 2014). The results showed that exosomes were significantly increased in Parkin-deficient fibroblasts (Fig. $3 A$ ). To confirm this finding, we conducted Western blot analysis using established markers of exosomes, TSG101 and Flotillin-1, and confirmed increased exosome secretion from Parkin-deficient fibroblasts. We next wished to confirm our findings in DA neurons, which are highly affected in patients carrying parkin mutations. To that end, we differentiated Parkin-deficient and control iPS cells into DA neurons, which are considered as the most relevant neuronal model to DA neurons in human brains. Both nanoparticle tracking and Western blot analysis with TSG101 and Flotillin-1 revealed a similar increase in secretion of exosomes in Parkin-deficient DA neurons (Fig. 3B). To further establish that this effect was Parkin-specific, we measured exosome release from HEK293 cells in which Parkin expression levels were modulated. The results showed that shRNA-mediated silencing of parkin resulted in increased exosome release (Fig. 3C), whereas overexpression of wild-type but not mutant Parkin led to a decrease in secretion of exosomes (Fig. 3D), suggesting that Parkin is negatively involved in exosome generation. Together, these results demonstrated the involvement of Parkin in exosome secretion in multiple cellular models.

\section{Parkin ubiquitinates and activates Rab7}

So far, we have demonstrated that Parkin controls the endocytic pathway through the regulation of retromer function, endosomal tubulation, ILV formation, and exosome secretion. To further examine the role of Parkin in the endocytic pathway on the molecular level, we searched for relevant candidates among putative Parkin substrates recently identified by unbiased mass spectrometry analysis (Bingol et al., 2014). One of the promising candidates was Rab7, a late endosomal small GTPase implicated in the late endosome/lysosome fusion (Bucci et al., 2000; Seals et al., 2000; Wurmser et al., 2000), endosomal maturation (Poteryaev et al., 2010), retromer function (Rojas et al., 2008; Seaman et al., 2009), and lysosomal tubulation in macrophages (Mrakovic et al., 2012). Interestingly, ILV accumulation has been observed upon rab7 knockdown (Vanlandingham and Ceresa, 2009). As a first step, we examined whether Parkin can ubiquitinate Rab7 by transfecting HEK293 cells with wild-type or mutant Parkin together with GFP-tagged Rab7 and HA-tagged UB. Ubiquitinated proteins were immunoprecipitated with anti-HA antibody, and anti-Rab7 antibody was used to detect ubiquitinated Rab7 by immunoblotting. We found that wild-type Parkin increased ubiquitination of Rab7, whereas Parkin-C431S, which contains a mutation in the UB acceptor site, had no effect (Fig. 4A), suggesting that Parkin can ubiquitinate Rab7. We also observed that the ubiquitination of Rab7 was decreased in Parkin-deficient DA neurons compared with control cells, suggesting that endogenous Rab7 was targeted by Parkin (Fig. $4 B$ ). To further examine whether Parkin ubiquitinated Rab7 directly, we performed an in vitro ubiquitination assay that showed GST-Rab7 ubiquitination in the presence of GST-Parkin and phosphomimetic UB (S65D), which can activate Parkin (Koyano et al., 2014) (Fig. 4C), sug- 
A

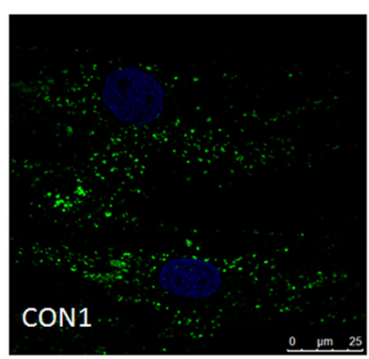

CD63/DAPI

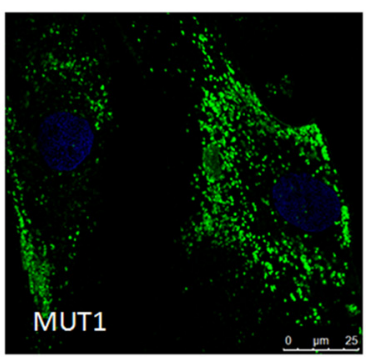

CON2

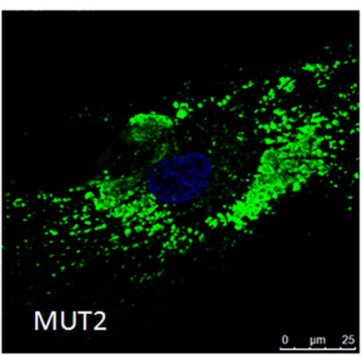

B
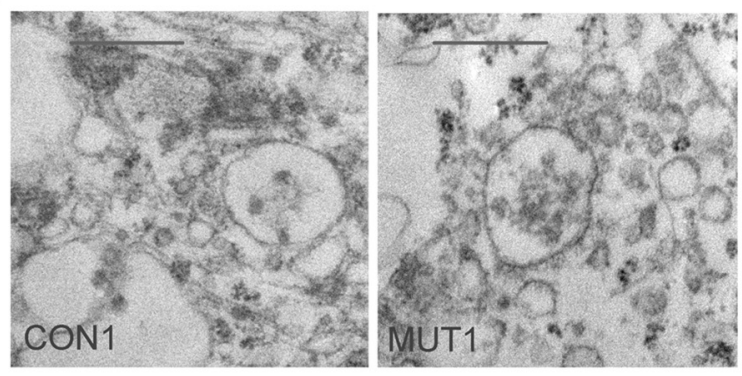
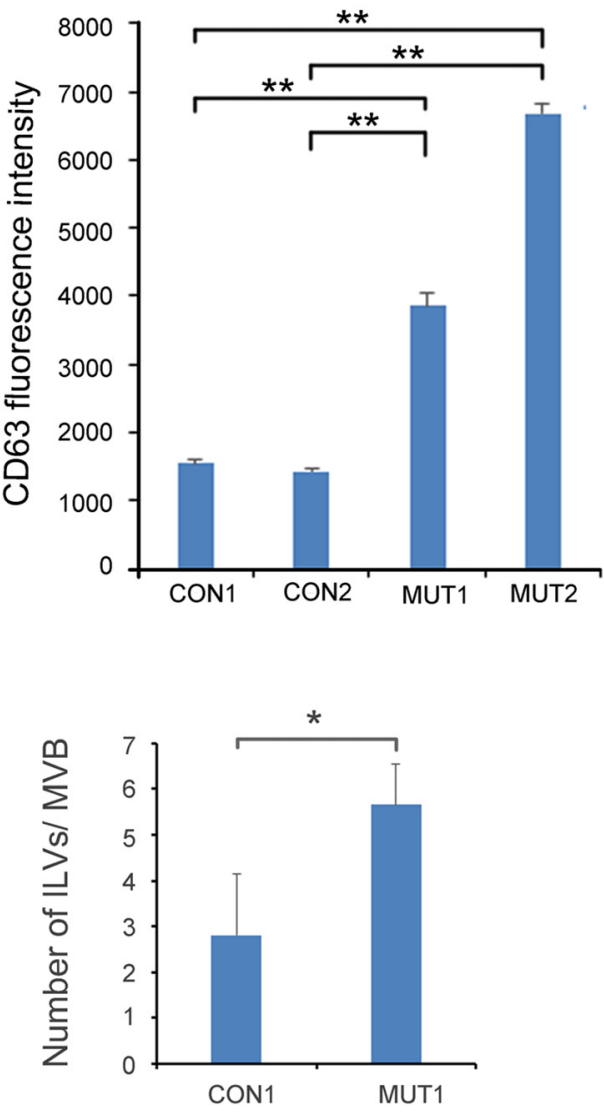

C
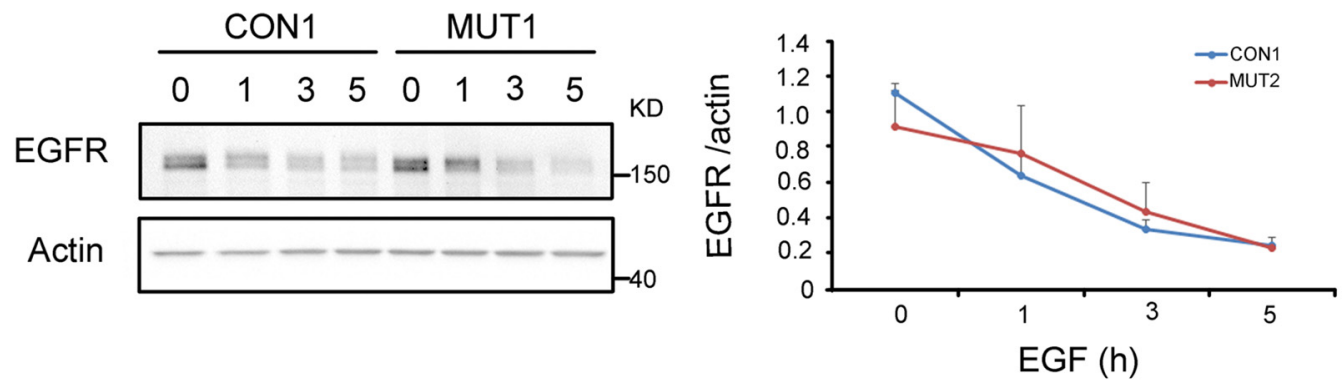

D
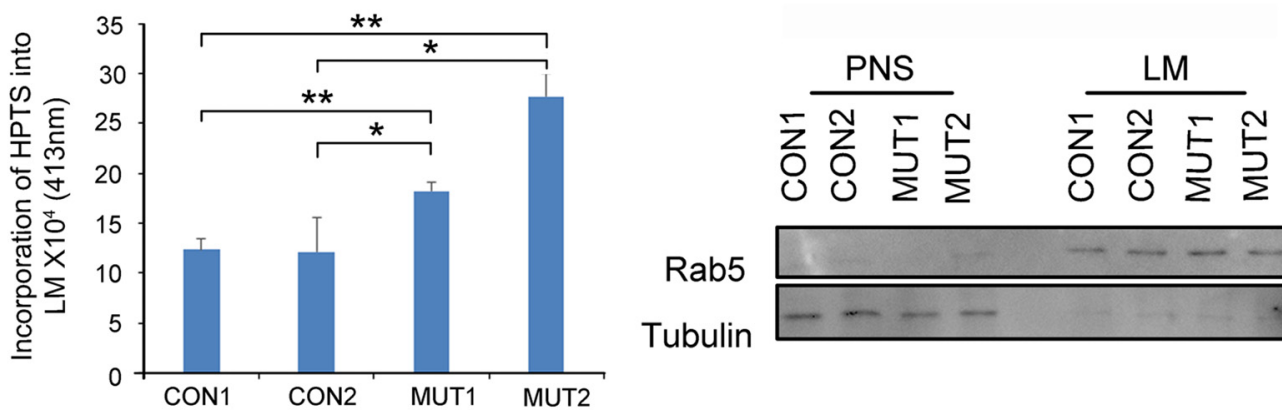

Rab5

Tubulin

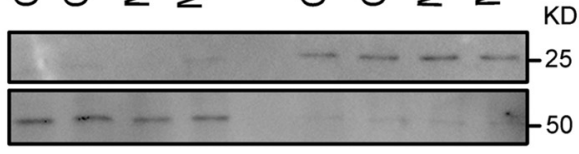

Figure 2. Increased membrane invagination and ILVs in Parkin-deficientfibroblasts. A, Left, Immunostaining analysis of CD63 (green) in Parkin-deficient (MUT1 and MUT2) and control (CON1 and CON2) fibroblasts. Blue represents DAPI. Scale bar, $25 \mu \mathrm{m}$. Right, Quantification of CD63 fluorescence intensities ( $N=3$ independent experiments). ${ }^{* *} p<0.01$. B, Left, Electron microscope images of ILVs in MVBs from control (CON1) and Parkin-deficient (MUT1) fibroblasts. Scale bar, $50 \mathrm{~nm}$. Right, Quantification analysis of the number of ILVs in MVBs ( $n=20$ cells). ${ }^{*} p<0.05$. C, EGFR degradation assay. Left, Parkin-deficient and control fibroblasts were incubated with $100 \mathrm{ng} / \mathrm{ml}$ EGF for indicated time points and analyzed by Western blots. Right, Quantification of EGFR level normalized to actin ( $N=3$ independent experiments). $\boldsymbol{D}$, Right, In vitro invagination assay. PNSs obtained from Parkin-deficient (MUT1 and MUT2) or control (CON1 and CON2) fibroblasts wereincubated with HPTS in the presence of salts and ATP-regenerating system. The excessive dye present in the solution is quenched with $p$-xylene-bis-pyridinium bromide, followed by flotation in sucrosegradient to isolate lightmembranes and measurement of fluorescence $\left(N=3\right.$ independent experiments). ${ }^{*} p<0.05$. ${ }^{* *} p<0.01$. Left, Equal amount of proteins from PNS and light membrane $(\mathrm{LM})$ fractions were detected by Western blot analysis of Rab5 and Tubulin to demonstrate the purification of $L M$. 
A
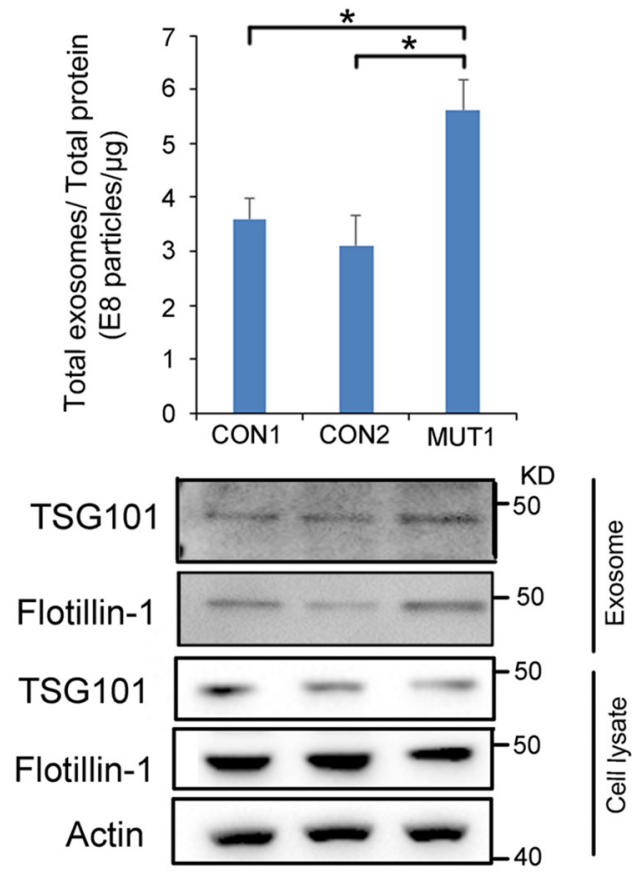

C
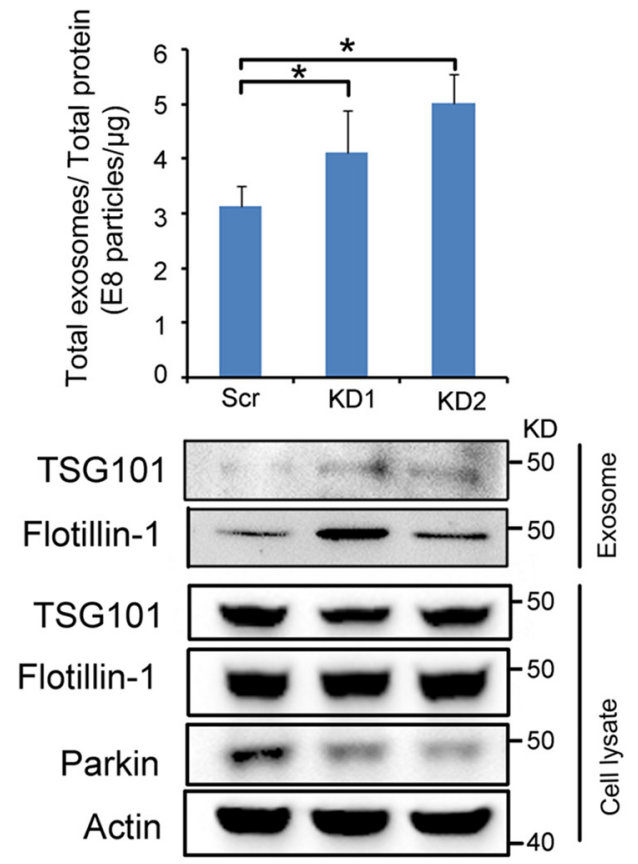

B
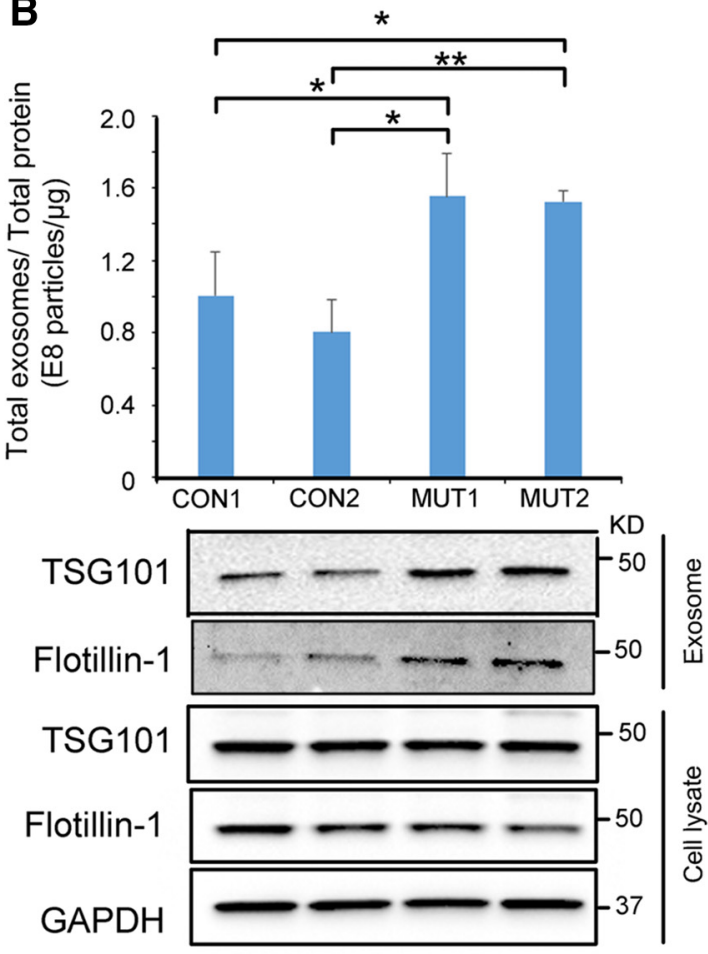

D

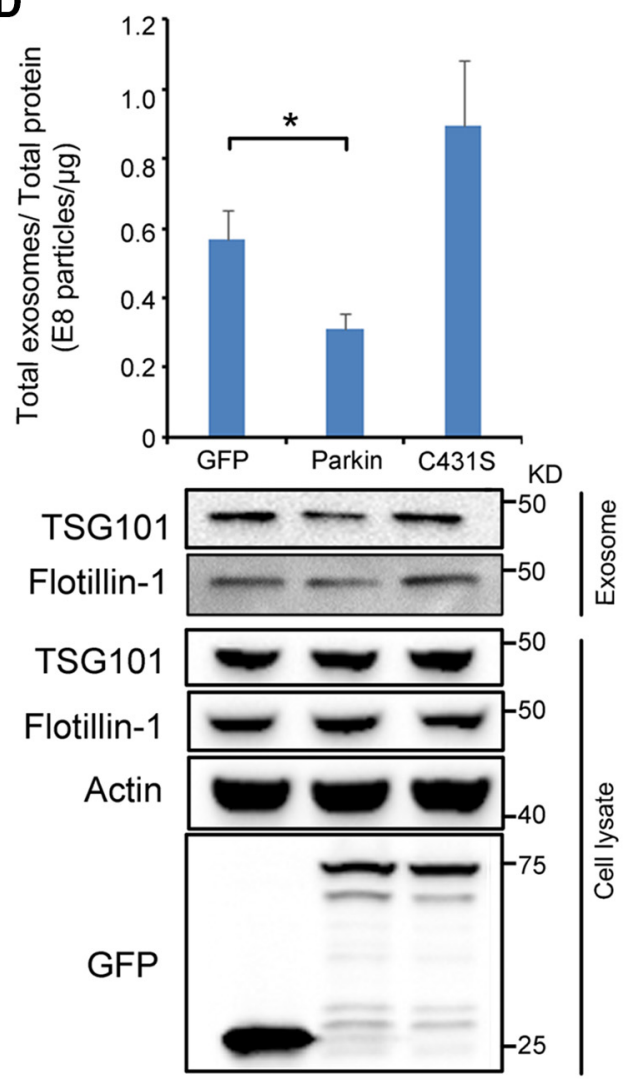

Figure 3. Parkin regulates exosome secretion. $\boldsymbol{A}$, Top, Quantification of exosome release in the media from Parkin-deficient (MUT1) or control (CON1 and CON2) fibroblasts ( $N=3$ independent experiments). ${ }^{*} p<0.05$. Bottom, Western blot analysis of TSG101 and Flotillin-1 in exosome and cell lysates. Actin was used as a loading control. $\boldsymbol{B}$, Top, Quantification of exosome release in the media from Parkin-deficient (MUT1 and MUT2) or control (CON1 and CON2) DA neurons ( $N=3$ independent experiments). ${ }^{*} p<0.05 .{ }^{* *} p<0.01$. Bottom, Western blot analysis of TSG101 and Flotillin-1 in exosome and cell lysates. GAPDH was used as a loading control. C, Top, Quantification of exosome release in the media from HEK293 cells transfected with scrambled or Parkin shRNA $\left(N=3\right.$ independent experiments). ${ }^{*} p<0.05$. Bottom, Western blot analysis of TSG101 and Flotillin-1 in exosomes and TSG101, Flotillin-1, and Parkin in cell lysates. Actin was used as a loading control. D, Top, Quantification of exosome release in the media from HEK293 cells transfected with wild-type Parkin, mutant C431S, or GFP vector ( $N=3$ independent experiments). ${ }^{*} p<0.05$. Bottom, Western blot analysis of TSG101 and Flotillin-1 in exosome and TSG101, Flotillin-1, and GFP in cell lysates. Actin was used as a loading control. 
A

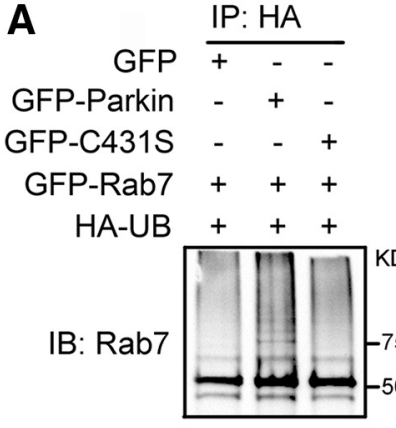

IB: HA

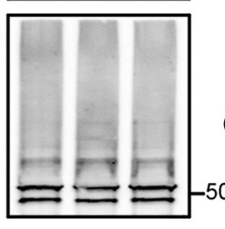

$\frac{\text { Input }}{+-}$

$-+$

$-\quad+$

$+++$

$+++$

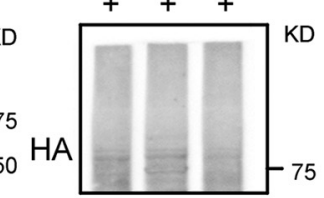

GFP

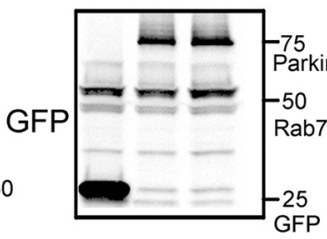

B

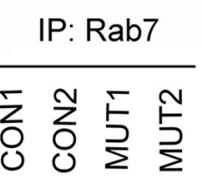

UB

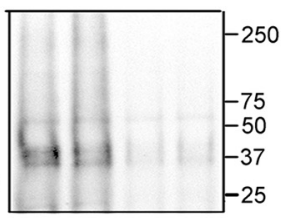

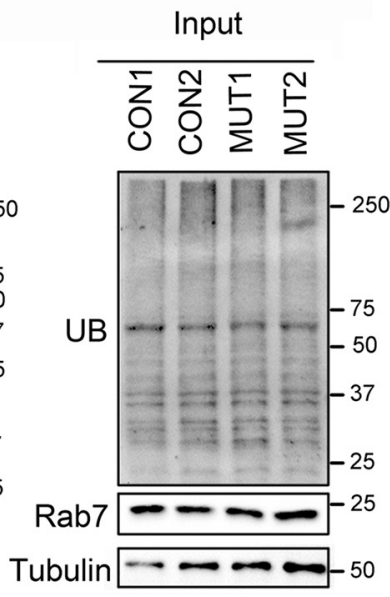

C

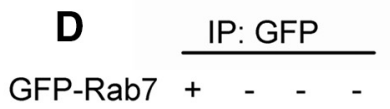

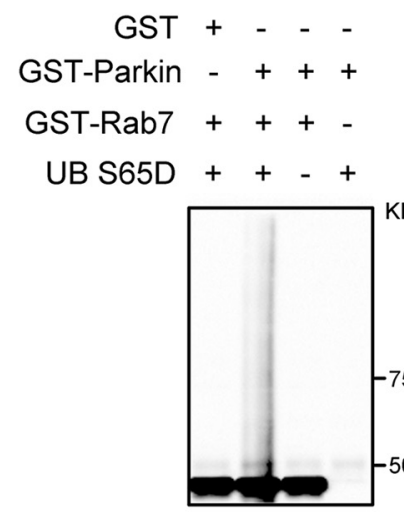

Rab7

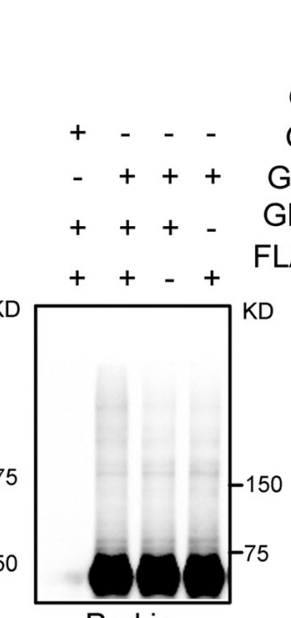

Parkin

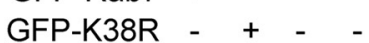

GFP-K191R - - +

GFP-K194R - - - +

FLAG-Parkin ++++

HA-UB ++++

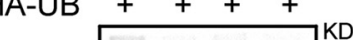

IB: HA

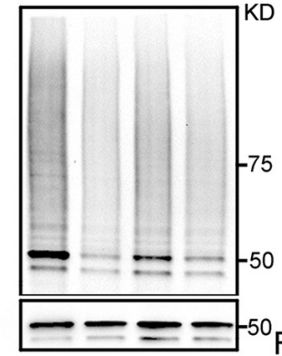

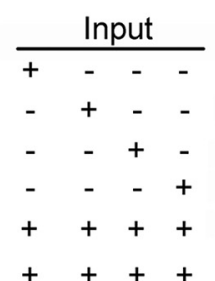

$++++$

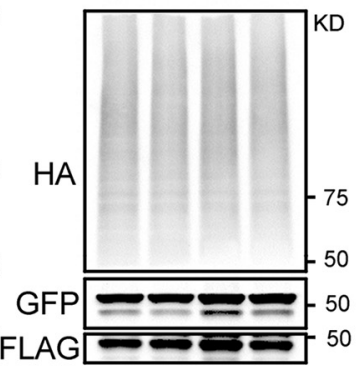

E

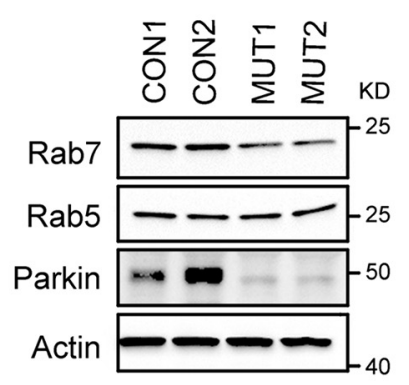

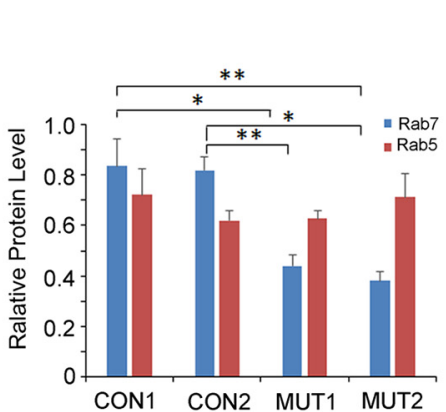

$\mathbf{F}$

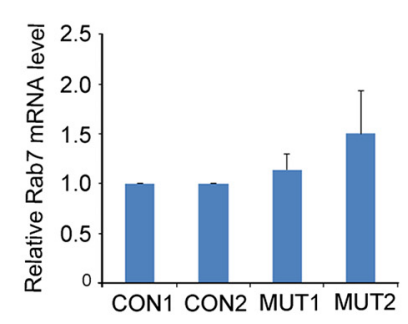

Figure 4. Parkin promotes ubiquitination of Rab7 and regulates its stability. $A$, Left, HEK293 cells were transfected with indicated constructs. Cell lysates were immunoprecipitated with anti-HA antibody and immunoblotted with anti-Rab7 antibody. HA was used as a loading control. Right, The 10\% of input shows the expression levels of each protein. $\boldsymbol{B}$, Left, Cell lysates from Parkin-deficient (MUT1 and MUT2) and control (CON1 and CON2) DA neurons were subjected to immunoprecipitation with anti-Rab7 antibody and immunoblotted with anti-UB and anti-Rab7 antibodies. Right, The 10\% of input shows each protein level in cell lysates. C, In vitro ubiquitination assay. GST-Rab7 protein was incubated with GST or GST-Parkin in the presence or absence of phosphomimetic UB (S65D) in the ubiquitination buffer system for $2 \mathrm{~h}$, and samples were subjected to Western blot and detected with anti-Rab7 and anti-Parkin antibodies. D, Left, HEK293 cells were transfected with indicated constructs, and cell lysates were immunoprecipitated with anti-GFP antibody and immunoblotted with anti-HA antibody. GFP was used as a loading control. Right, The $10 \%$ of input shows the expression levels of each protein. E, Left, Western blot analysis of Rab7, Rab5, and Parkin in fibroblasts from 2 controls (CON1 and CON2) and 2 PD patients with mutant Parkin (MUT1 and MUT2). Actin was used as a loading control. Right, Quantification of the protein levels. Rab7 and Rab5 levels were normalized to actin $\left(N=3\right.$ independent experiments). ${ }^{*} p<$ $0.05 .{ }^{* *} p<0.01$. F, Quantification analysis of Rab7 mRNA by real-time PCR from Parkin-deficient (MUT1 and MUT2) and 2 control (CON1 and CON2) fibroblasts.

gesting that the regulation of Rab7 ubiquitination by Parkin was direct. To identify the specific lysine residues targeted by Parkin, we generated several GFP-tagged Rab7 K-to-R mutants according to reported Rab7 ubiquitination sites in vivo (Kim et al., 2011; Wagner et al., 2011; Mertins et al., 2013), including K38R, K191R, and K194R. HEK293 cells were transfected with these K-to-R mutants together with FLAG-Parkin and HA-UB. While ubiquitination of each of the three mutants was reduced compared with wild-type Rab7, the K38R mutation showed the most dramatic effect (Fig. 4D). These results suggested that Parkin pro- 
A

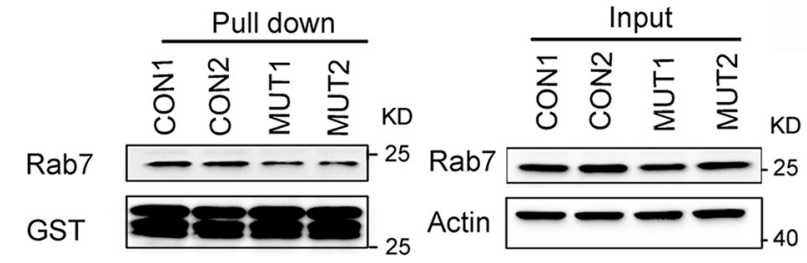

B

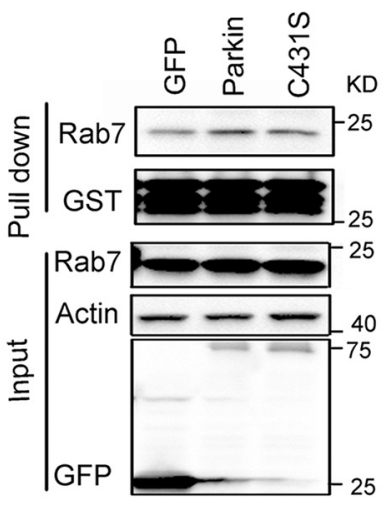

C
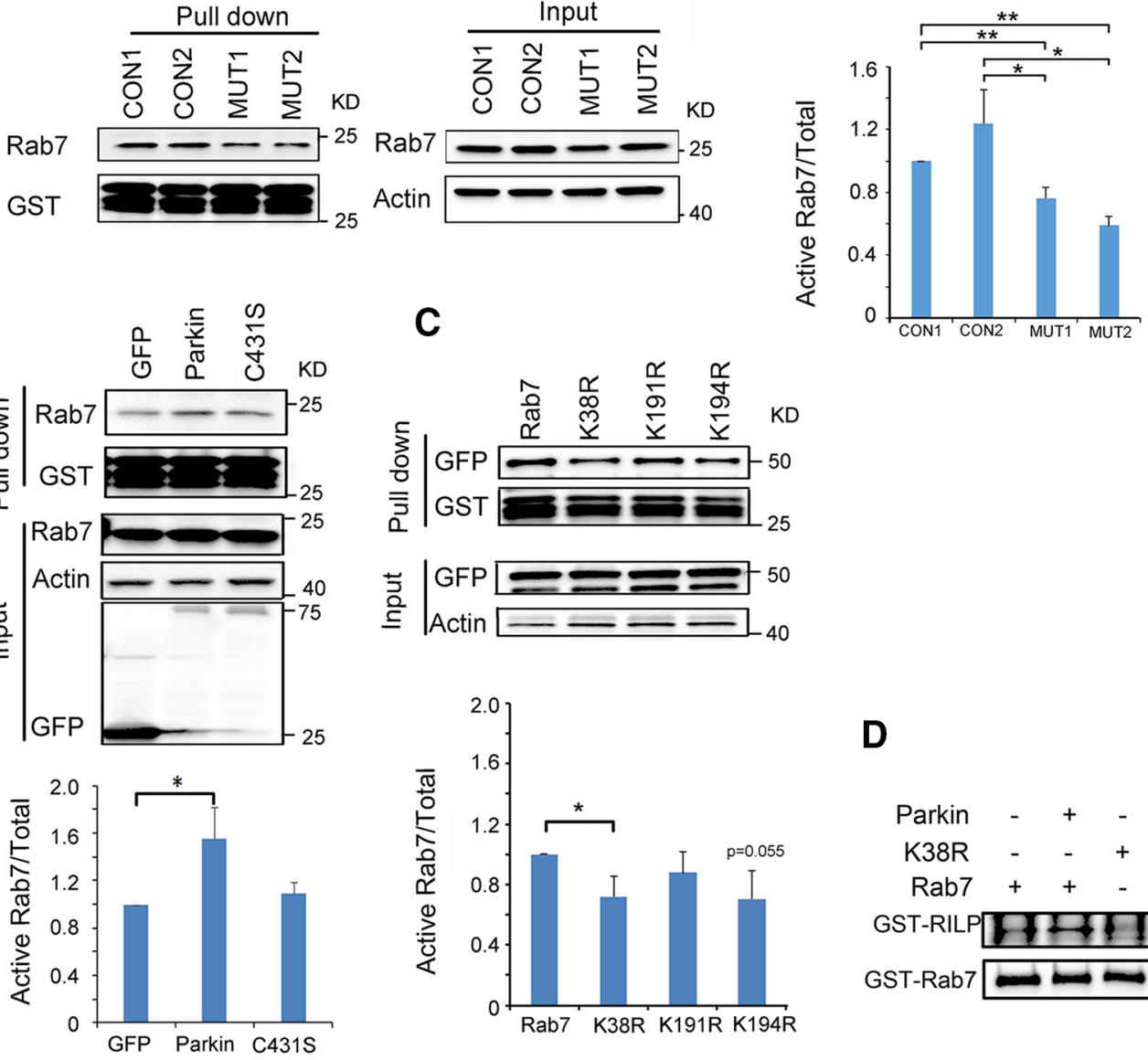

D

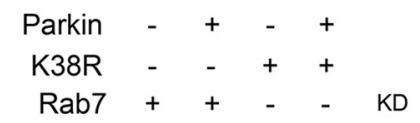
GST-RILP IRHI]
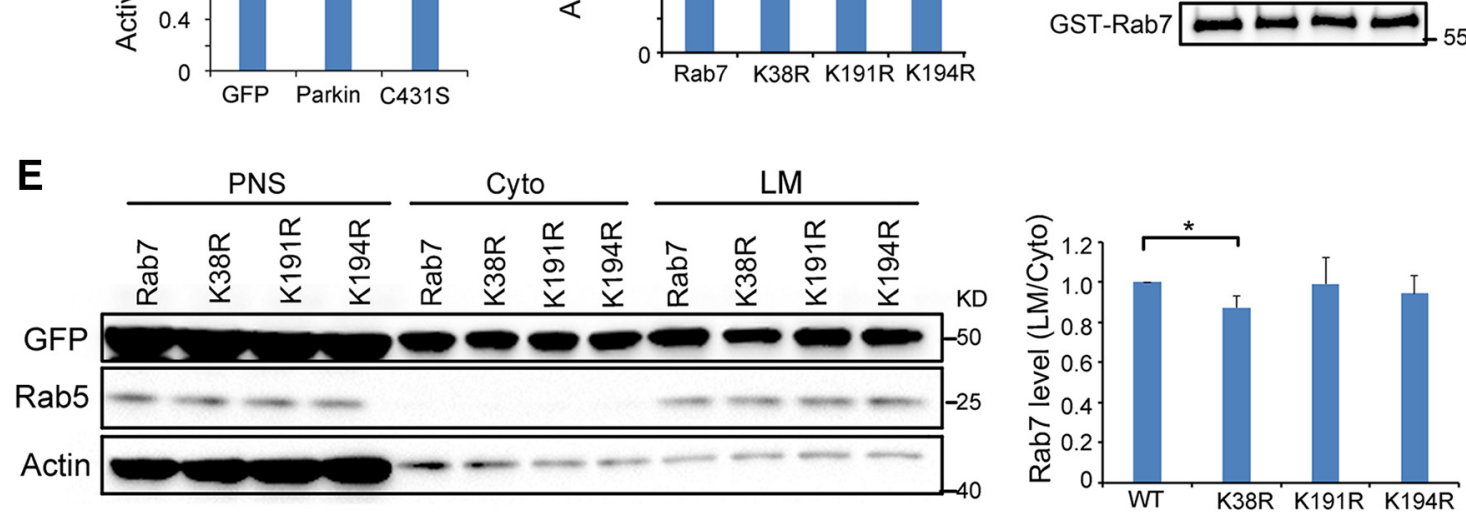

$\mathbf{F}$
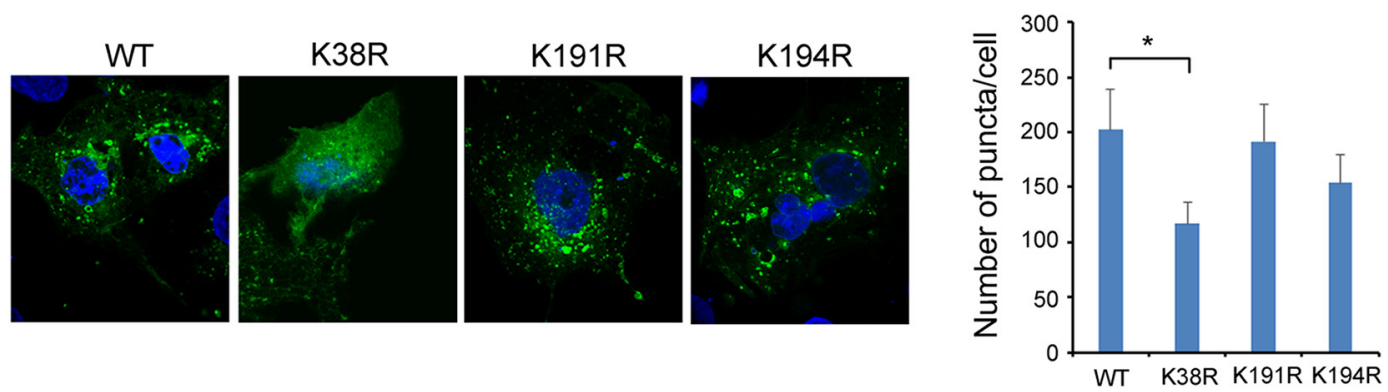

Figure 5. Parkin regulates Rab7 activity. A, Left, Parkin-deficient (MUT1 and MUT2) and control (CON1 and CON2) fibroblast extracts were subjected to GST-RILP pull-down assay and detected with anti-Rab7 antibody. GST was used as a loading control. Middle, The $10 \%$ of input shows the expression levels of Rab7. Actin was used as a loading control. Right, Quantification analysis of active Rab7. The amount of Rab7 isolated by GST-RILP normalized to GST level versus total (input) Rab7 normalized to actin ( $N=3$ independent experiments). ${ }^{*} p<0.05 .{ }^{* *} p<0.01 . B$, Top, HEK293 cells were transfected with indicated constructs, endogenous active Rab7 isolated by GST-RILP, and detected by anti-Rab7 antibody. GST was used as a loading control. Middle, The 10\% input shows the total level of Rab7 and the overexpression level of wild-type and mutant Parkin. Actin was used as a loading control. Bottom, Quantification of the active Rab7. The amount of Rab7 isolated by GST-RILP normalized to GST versus total (input) Rab7 normalized to actin ( $N=3$ independent experiments). ${ }^{*} p<0.05$. C, Top, HEK293 cells were transfected with indicated constructs, cell lysates subjected to GST-RILP pull-down, and active Rab7 detected by anti-GFP antibody. GST was used as a loading control. Middle, The 10\% input shows the expression level of Rab7. Actin was used as a loading control. Bottom, Quantification of active Rab7. The amount of Rab7 isolated by GST-RILP normalized to GST versus total (input) Rab7 normalized to actin ( $N=3$ independent experiments). ${ }^{*} p<0.05 . D$, GST-Rab7 or GST-K38R mutant protein was incubated with or without GST-Parkin in the presence of phosphomimetic UB (S65D), followed by incubation with GST-RILP fusion protein. Samples were immunoprecipitated with anti-Rab7 antibody and immunoblotted with anti-GST antibody. E, Left, HEK 293 cells transfected with indicated constructs. (Figure legend continues.) 
motes the ubiquitination of Rab7 on multiple lysines, with a preference for Lysine 38.

Ubiquitination as a post-translational modification has multiple roles, one of which is tagging proteins for proteasomal degradation (Glickman and Ciechanover, 2002). Hence, we initially hypothesized that decreased ubiquitination of Rab7 might lead to increased levels of Rab7 in the absence of functional Parkin. However, contrary to our expectations, a significant decrease in Rab7 levels was detected in Parkin-deficient fibroblast compared with controls (Fig. 4E). To examine whether this decrease in Rab7 protein was due to altered gene expression, we analyzed Rab7 mRNA levels and found no differences between controls and Parkin-deficient fibroblasts (Fig. $4 F$ ). These results suggested that the observed decrease in Rab7 occurred at the protein level and raised the possibility that Parkin mutations may affect Rab7 stability. It has been shown that Rab9 GTPase requires effector interaction for its stability (Ganley et al., 2004). We hypothesized that the same principle might apply to other Rabs where decreased levels of Rab7 in Parkin-deficient cells would be due to diminished effector binding. To test this hypothesis, we measured the capacity of Rab7 to bind its effector Rab7-Interacting Lysosomal Protein (RILP) by performing a GST pull-down assay using Rab7-binding domain of RILP (Romero Rosales et al., 2009; Peralta et al., 2010). We found that the ratio of RILP-bound and total Rab7 was decreased in Parkin-deficient fibroblasts compared with controls (Fig. 5A), suggesting decreased binding between Rab7 and RILP in Parkin-deficient cells. To further substantiate this conclusion, we performed the same RILPbinding assay upon overexpression of wild-type Parkin. As shown in Figure $5 B$, the ratio of endogenous RILP-bound versus total Rab7 was increased in cells overexpressing wild-type Parkin but not in the presence of mutant Parkin C431S. These results suggested that Parkin regulates RILP-binding capacity of Rab7.

Because our data suggested that Parkin primarily ubiquitinates Rab7 at the specific lysine (K38) (Fig. 4D), we analyzed whether Parkin affects Rab7-RILP interaction through ubiquitination of Rab7. Using GST-RILP pull-down assay, we examined the RILP-binding capacity of Rab7 K-to-R mutants compared with wild-type Rab7. These results showed that the ratio of RILPbound versus total Rab7 was significantly decreased in the presence of K38R mutant (Fig. 5C), suggesting that ubiquitination of Rab7 primarily on K38 residue promotes its affinity for RILP. To further confirm this conclusion, we examined the RILP binding property of ubiquitinated Rab7. As shown in Figure $5 D$, levels of coimmunoprecipitated GST-RILP were increased in the presence of wild-type but not K38R mutant Rab7, suggesting that ubiquitinated Rab7 exhibited stronger binding to the GST-RILP fusion protein compared with unmodified Rab7 (Fig. 5D).

Because Rab GTPases must be active to interact with their effectors, we hypothesized that Parkin-mediated ubiquitination might increase Rab7 activity. Activation stabilizes membrane association of Rab GTPases, which normally cycle between the cytosol and their target membranes (Barr, 2013). To test

$\leftarrow$

(Figure legend continued.) PNSs were prepared by flotation in sucrose step gradients to isolate LMs. Proteins were detected by anti-GFP antibody. Rab5 and actin were used as the loading controls for light membrane and cytosolic (Cyto) fraction, respectively. Right, Quantification of active Rab7. Rab7 in LM fraction was normalized to Rab5 level versus Rab7 in cytosolic fraction normalized to actin ( $N=3$ independent experiments). ${ }^{*} p<0.05$. $\boldsymbol{F}$, Left, Confocal images of GFP-tagged wild-type or K to R mutant Rab7 (green) in Cos 7 cells. Blue represents DAPI. Right, Quantification of the membrane-associated Rab7 (puncta) in cells ( $N=3$ independent experiments). ${ }^{*} p<0.05$.
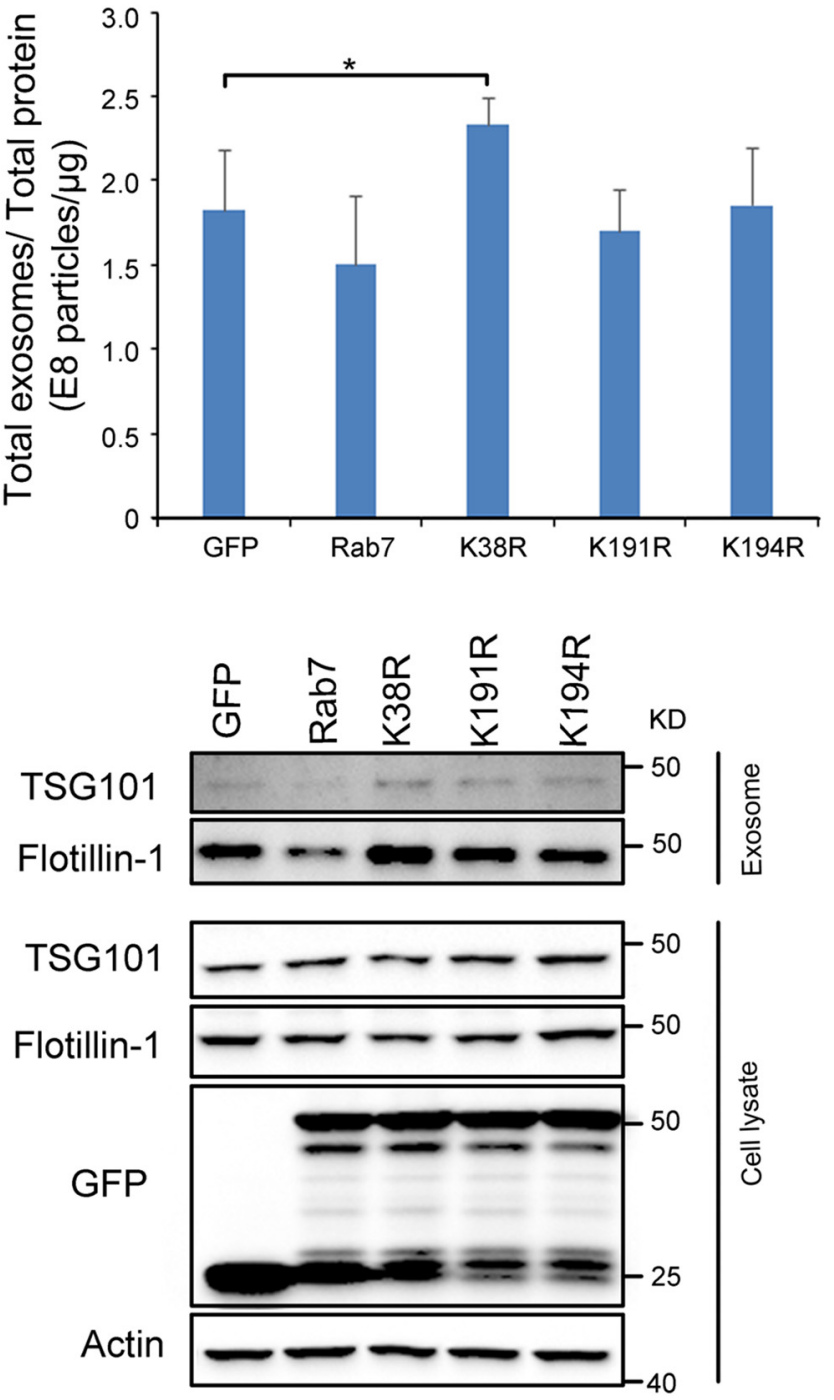

Figure 6. Exosome secretion was increased in HEK 293 cell expression Rab7 K38R mutants Top, Quantification of exosome release in the media from HEK293 cells transfected with wildtype, K38R, K191R, or K194R mutant Rab7 ( $N=3$ independent experiments). ${ }^{*} p<0.05$. Bottom, Western blot analysis of TSG101 and Flotillin-1 in exosomes and TSG101, Flotillin-1, and GFP in cell lysates. Actin was used as loading control.

whether K38-ubiquitination promotes cytosol-to-membrane translocation of Rab7, we expressed GFP-tagged wild-type Rab7 or K-to-R mutants in HEK293 cells and performed cell fractionation assay to separate endosome-enriched light membranes (LMs) from the cytosol by floatation of PNSs on sucrose density gradients (Gorvel et al., 1991; Aniento et al., 1993). The results from Western blot analysis showed that the ratio of Rab7 K38R mutant in LM versus total PNS levels was significantly decreased (Fig. $5 E$ ). To confirm these results, we analyzed the distribution pattern of wild-type and mutant Rab7 in COS7 cells by immunofluorescence. We observed a reduced number of punctate profiles for Rab7 K38R mutant compared with wild-type Rab7, consistent with its diminished LM/endosome association (Fig. $5 F$ ). Together, these results suggested that Parkin loss of function leads to a decrease in ubiquitination and membrane association of Rab7.

Next, we asked whether Parkin deficiency-induced endosomal phenotype can be explained, at least in part, by diminished activity or ubiquitination status of Rab7. It has been reported that Rab7 contributes to the retromer recruitment (Rojas et al., 2008). 
Accumulation of ILVs has been observed upon rab7 knockdown in HeLa cells (Vanlandingham and Ceresa, 2009), whereas Rab7 dominant-negative mutant prevented lysosomal tubulation in macrophages (Mrakovic et al., 2012), suggesting the involvement of Rab7 in the formation of ILVs and tubules. However, the role of Rab7 in exosome formation remains controversial; one group found that Rab7 knockdown significantly impaired the release of syntenin-positive exosomes in MCF-7 cells (Baietti et al., 2012), whereas another study failed to establish association between Rab7 and exosome release (Ostrowski et al., 2010). To specifically test the effect of Rab7 ubiquitination on exosome release, we overexpressed wild-type Rab7 or its K-to-R mutants in HEK cells and measured exosome number using nanoparticle tracking analysis and Western blot approaches. Similar to Parkin deficiency, overexpression of K38R Rab7 mutant led to increased exosome release (Fig. 6), suggesting that Rab7 ubiquitination deficiency may be at least partially responsible for the increase in exosome secretion associated with Parkin loss of function.

\section{Discussion}

In this study, we found that Parkin modulates endocytic pathway through the regulation of tubular and multivesicular domain organization of late endosomes, retromer function, and the formation of ILVs and exosomes. We also show that Parkin ubiquitinates lateendosomal GTPase Rab7 and regulates its levels and effectorbinding properties, which might be at least partially responsible for the observed changes in endosomal morphology and membrane dynamics in Parkin-deficient cells. These perturbations in endolysosomal system that were detected in Parkin-deficient cellular models influence important cellular functions and may contribute to the development of PD pathology in multiple ways. Importantly, M6PR and its retromer-dependent endosome-to-Golgi retrieval are essential for the transport of lysosomal enzymes (Arighi et al., 2004). Hence, the impairment of this pathway can lead to lysosomal dysfunction, a hallmark of several neurodegenerative diseases, including PD (Nixon, 2013; Perrett et al., 2015; Small and Petsko, 2015). On the other hand, exosomes have been receiving increasing attention as the potential carriers of the toxic forms of a-Syn, the secretion of which might participate in the propagation of pathology within PD-affected brains (Emmanouilidou et al., 2010; Alvarez-Erviti et al., 2011). In this study, we demonstrate accelerated ILV formation and increased amounts of CD63-positive intraluminal membranes in patient-derived Parkin-deficient fibroblasts. We also detected an increase in exosome release in multiple Parkin-deficient models: patient-derived fibroblasts, iPS-derived DA neurons, and HEK293 cells upon parkin knockdown. Interestingly, it has been reported that a-Syn overexpression in parkin deletion mouse models resulted in increased a-Syn secretion from the brain into the blood (Lonskaya et al., 2013). It is tempting to speculate that the increased exosome release in Parkin-deficient cells might correlate with a-Syn secretion.

Although Rab7 has been suggested to be involved in mediating Parkin function as an effector of TBC1D15 and TBC1D17 to regulate autophagosome morphogenesis (Yamano et al., 2014), our study reveals another important aspect of Parkin-dependent modulation of endo-lysosomal pathway: ubiquitination of Rab7 directly on K38 residue and regulation of its levels and RILPbinding capacity. This lysine is conserved among several Rab GTPases; it is located within the effector-interacting domain of Rab7 (Bruckert et al., 2000), and its counterpart in Rab34, K82, is essential for interaction with RILP (Wang and Hong, 2002). Hence, one plausible scenario would be that the UB chain added by Parkin enhances the RILP-Rab7 binding. Diminished interaction with RILP could then affect Rab7 stability/half-life in Parkin- deficient cells, analogous to the reported effector-regulated half-life of Rab9 (Ganley et al., 2004). We also show that the K38R mutation decreases Rab7 association with the light membranes, suggesting that the activity of Rab7 is impaired. A traditional view is that Rab GTPases activity is regulated by guanine nucleotide exchange factor and GTPase activating protein. Our data suggest possible additional level of activity regulation for Rab7, through Parkin-mediated ubiquitination. Similarly, a recent report showed that $\beta 2$ AR-HACE1 complex regulates Rab1la activity through ubiquitination (Lachance et al., 2014). Together, these studies imply an interesting possibility that ubiquitination might represent a rather general mechanism for modulating Rab function.

We found that parkin mutations influence tubulation and ILV abundance in endosomes, but not the pattern of LAMP1 staining and EGFR degradation, suggesting that only a subset of Rab7associated processes were affected. This could be explained by potential ubiquitination by Parkin of additional factors implicated in shaping of the endo-lysosomal system, or by differential Rab7 dose dependence for each of these processes. However, it is tempting to speculate that Parkin-mediated ubiquitination of Rab7 directly modifies its specific effector affinities. This is particularly interesting in light of opposing functions for some Rab7 effectors. For instance, Rab7 effector RILP induces vesicular movement toward the minus-end of microtubule through the recruitment of dynein/dynactin complex (Jordens et al., 2001), whereas another effector FYCO1 mediates a plus-end directed movement through its interaction with kinesin (Pankiv et al., 2010). Reversible ubiquitination might navigate the competition between RILP and FYCO1 for the opposing movements to coordinate vesicular transport.

The exact mechanism of Parkin deficiency/Rab7-K38R-mediated positive regulation of exosome secretion is still unclear. Controversially, one study shows that the reduced Rab7 levels led to a decrease in exosome secretion (Baietti et al., 2012). However, if the lack of specific K38 ubiquitination could modify the effectorbinding pattern of Rab7, the net result might be a change in some of the exosome biogenesis aspects, such as the ILV formation or endosome motility, which ultimately leads to a perceived increase in exosomes. Further studies are needed to thoroughly explore this possibility.

Interestingly, Rab7 has already been implicated in other genetic forms of Parkinson's disease, such as LRRK2 mutation-induced PD (Gómez-Suaga et al., 2014). Moreover, a-Syn aggregates present in PD impair retrograde axonal transport of Rab7 endosomes (Volpicelli-Daley et al., 2014). Increasing Rab7 activity by enhancing its ubiquitination might be a potential therapeutic strategy for PD.

In conclusion, our study reveals a novel role for Parkin in regulating endo-lysosomal pathway through modulating endosomal domain organization, retromer pathway, exosome release, and Rab7 levels and activity. These findings raise a possibility that alterations in the endo-lysosomal system contribute to the development of pathology in Parkin-linked Parkinson's disease.

\section{References}

Alvarez-Erviti L, Seow Y, Schapira AH, Gardiner C, Sargent IL, Wood MJ, Cooper JM (2011) Lysosomal dysfunction increases exosome-mediated alpha-synuclein release and transmission. Neurobiol Dis 42:360-367. CrossRef Medline

Aniento F, Emans N, Griffiths G, Gruenberg J (1993) Cytoplasmic dyneindependent vesicular transport from early to late endosomes. J Cell Biol 123:1373-1387. CrossRef Medline

Arighi CN, Hartnell LM, Aguilar RC, Haft CR, Bonifacino JS (2004) Role of the mammalian retromer in sorting of the cation-independent mannose 6-phosphate receptor. J Cell Biol 165:123-133. CrossRef Medline 
Baietti MF, Zhang Z, Mortier E, Melchior A, Degeest G, Geeraerts A, Ivarsson Y, Depoortere F, Coomans C, Vermeiren E, Zimmermann P, David G (2012) Syndecan-syntenin-ALIX regulates the biogenesis of exosomes. Nat Cell Biol 14:677-685. CrossRef Medline

Barr FA (2013) Review series. Rab GTPases and membrane identity: causal or inconsequential? J Cell Biol 202:191-199. CrossRef Medline

Bingol B, Tea JS, Phu L, Reichelt M, Bakalarski CE, Song Q, Foreman O, Kirkpatrick DS, Sheng M (2014) The mitochondrial deubiquitinase USP30 opposes parkin-mediated mitophagy. Nature 510:370-375. CrossRef Medline

Brankatschk B, Pons V, Parton RG, Gruenberg J (2011) Role of SNX16 in the dynamics of tubulo-cisternal membrane domains of late endosomes. PLoS One 6:e21771. CrossRef Medline

Bruckert F, Laurent O, Satre M (2000) Rab7, a multifaceted GTP-binding protein regulating access to degradative compartments in eukaryotic cells. Protoplasma 210:108-116. CrossRef

Bucci C, Thomsen P, Nicoziani P, McCarthy J, van Deurs B (2000) Rab7: a key to lysosome biogenesis. Mol Biol Cell 11:467-480. CrossRef Medline

Chambers SM, Fasano CA, Papapetrou EP, Tomishima M, Sadelain M, Studer L (2009) Highly efficient neural conversion of human ES and iPS cells by dual inhibition of SMAD signaling. Nat Biotechnol 27:275-280. CrossRef Medline

Cookson MR (2009) alpha-Synuclein and neuronal cell death. Mol Neurodegener 4:9. CrossRef Medline

Dragovic RA, Gardiner C, Brooks AS, Tannetta DS, Ferguson DJ, Hole P, Carr B, Redman CW, Harris AL, Dobson PJ, Harrison P, Sargent IL (2011) Sizing and phenotyping of cellular vesicles using Nanoparticle Tracking Analysis. Nanomedicine 7:780-788. CrossRef Medline

Emmanouilidou E, Melachroinou K, Roumeliotis T, Garbis SD, Ntzouni M, Margaritis LH, Stefanis L, Vekrellis K (2010) Cell-produced alphasynuclein is secreted in a calcium-dependent manner by exosomes and impacts neuronal survival. J Neurosci 30:6838-6851. CrossRef Medline

Falguières T, Luyet PP, Bissig C, Scott CC, Velluz MC, Gruenberg J (2008) In vitro budding of intralumenal vesicles into late endosomes is regulated by Alix and Tsg101. Mol Biol Cell 19:4942-4955. CrossRef Medline

Fallon L, Bélanger CM, Corera AT, Kontogiannea M, Regan-Klapisz E, Moreau F, Voortman J, Haber M, Rouleau G, Thorarinsdottir T, Brice A, van Bergen En Henegouwen PM, Fon EA (2006) A regulated interaction with the UIM protein Eps15 implicates parkin in EGF receptor trafficking and PI(3)K-Akt signalling. Nat Cell Biol 8:834-842. CrossRef Medline

Ganley IG, Carroll K, Bittova L, Pfeffer S (2004) Rab9 GTPase regulates late endosome size and requires effector interaction for its stability. Mol Biol Cell 15:5420-5430. CrossRef Medline

Gegg ME, Cooper JM, Chau KY, Rojo M, Schapira AH, Taanman JW (2010) Mitofusin 1 and mitofusin 2 are ubiquitinated in a PINK1/parkindependent manner upon induction of mitophagy. Hum Mol Genet 19: 4861-4870. CrossRef Medline

Geisler S, Holmström KM, Skujat D, Fiesel FC, Rothfuss OC, Kahle PJ, Springer W (2010) PINK1/Parkin-mediated mitophagy is dependent on VDAC1 and p62/SQSTM1. Nat Cell Biol 12:119-131. CrossRef Medline

Glickman MH, Ciechanover A (2002) The ubiquitin-proteasome proteolytic pathway: destruction for the sake of construction. Physiol Rev 82: 373-428. CrossRef Medline

Gómez-Suaga P, Rivero-Ríos P, Fdez E, Blanca Ramírez M, Ferrer I, Aiastui A, López De Munain A, Hilfiker S (2014) LRRK2 delays degradative receptor trafficking by impeding late endosomal budding through decreasing Rab7 activity. Hum Mol Genet 23:6779-6796. CrossRef Medline

Gorvel JP, Chavrier P, Zerial M, Gruenberg J (1991) rab5 controls early endosome fusion in vitro. Cell 64:915-925. CrossRef Medline

Gruenberg J (2001) The endocytic pathway: a mosaic of domains. Nat Rev Mol Cell Biol 2:721-730. CrossRef Medline

Hunn BH, Cragg SJ, Bolam JP, Spillantini MG, Wade-Martins R (2015) Impaired intracellular trafficking defines early Parkinson's disease. Trends Neurosci 38:178-188. CrossRef Medline

Imaizumi Y, Okada Y, Akamatsu W, Koike M, Kuzumaki N, Hayakawa H, Nihira T, Kobayashi T, Ohyama M, Sato S, Takanashi M, Funayama M, Hirayama A, Soga T, Hishiki T, Suematsu M, Yagi T, Ito D, Kosakai A, Hayashi K, et al. (2012) Mitochondrial dysfunction associated with increased oxidative stress and alpha-synuclein accumulation in PARK2 iPSC-derived neurons and postmortem brain tissue. Mol Brain 5:35. CrossRef Medline
Jordens I, Fernandez-Borja M, Marsman M, Dusseljee S, Janssen L, Calafat J, Janssen H, Wubbolts R, Neefjes J (2001) The Rab7 effector protein RILP controls lysosomal transport by inducing the recruitment of dyneindynactin motors. Curr Biol 11:1680-1685. CrossRef Medline

Kim W, Bennett EJ, Huttlin EL, Guo A, Li J, Possemato A, Sowa ME, Rad R, Rush J, Comb MJ, Harper JW, Gygi SP (2011) Systematic and quantitative assessment of the ubiquitin-modified proteome. Mol Cell 44:325340. CrossRef Medline

Klein C, Krainc D (2012) Movement disorders in 2011: translating new research findings into clinical practice. Nat Rev Neurol 8:65-66. CrossRef Medline

Kobayashi T, Vischer UM, Rosnoblet C, Lebrand C, Lindsay M, Parton RG, Kruithof EK, Gruenberg J (2000) The tetraspanin CD63/lamp3 cycles between endocytic and secretory compartments in human endothelial cells. Mol Biol Cell 11:1829-1843. CrossRef Medline

Kowal J, Tkach M, Théry C (2014) Biogenesis and secretion of exosomes. Curr Opin Cell Biol 29:116-125. CrossRef Medline

Koyano F, Okatsu K, Kosako H, Tamura Y, Go E, Kimura M, Kimura Y, Tsuchiya H, Yoshihara H, Hirokawa T, Endo T, Fon EA, Trempe JF, Saeki Y, Tanaka K, Matsuda N (2014) Ubiquitin is phosphorylated by PINK1 to activate parkin. Nature 510:162-166. CrossRef Medline

Kriks S, Shim JW, Piao J, Ganat YM, Wakeman DR, Xie Z, Carrillo-Reid L, Auyeung G, Antonacci C, Buch A, Yang L, Beal MF, Surmeier DJ, Kordower JH, Tabar V, Studer L (2011) Dopamine neurons derived from human ES cells efficiently engraft in animal models of Parkinson's disease. Nature 480:547-551. CrossRef Medline

Lachance V, Degrandmaison J, Marois S, Robitaille M, Génier S, Nadeau S, Angers S, Parent JL (2014) Ubiquitylation and activation of a Rab GTPase is promoted by a beta(2)AR-HACE1 complex. J Cell Sci 127:111123. CrossRef Medline

Lonskaya I, Desforges NM, Hebron ML, Moussa CE (2013) Ubiquitination increases parkin activity to promote autophagic alpha-synuclein clearance. PLoS One 8:e83914. CrossRef Medline

Malik BR, Godena VK, Whitworth AJ (2015) VPS35 pathogenic mutations confer no dominant toxicity but partial loss of function in Drosophila and genetically interact with parkin. Hum Mol Genet 24:6106-6117. CrossRef Medline

Mazzulli JR, Xu YH, Sun Y, Knight AL, McLean PJ, Caldwell GA, Sidransky E, Grabowski GA, Krainc D (2011) Gaucher disease glucocerebrosidase and alpha-synuclein form a bidirectional pathogenic loop in synucleinopathies. Cell 146:37-52. CrossRef Medline

Mertins P, Qiao JW, Patel J, Udeshi ND, Clauser KR, Mani DR, Burgess MW, Gillette MA, Jaffe JD, Carr SA (2013) Integrated proteomic analysis of post-translational modifications by serial enrichment. Nat Methods 10: 634-637. CrossRef Medline

Mrakovic A, Kay JG, Furuya W, Brumell JH, Botelho RJ (2012) Rab7 and Arl8 GTPases are necessary for lysosome tubulation in macrophages. Traffic 13:1667-1679. CrossRef Medline

Narendra D, Tanaka A, Suen DF, Youle RJ (2008) Parkin is recruited selectively to impaired mitochondria and promotes their autophagy. J Cell Biol 183:795-803. CrossRef Medline

Nixon RA (2013) The role of autophagy in neurodegenerative disease. Nat Med 19:983-997. CrossRef Medline

Numrich J, Ungermann C (2014) Endocytic Rabs in membrane trafficking and signaling. Biol Chem 395:327-333. CrossRef Medline

Ostrowski M, Carmo NB, Krumeich S, Fanget I, Raposo G, Savina A, Moita CF, Schauer K, Hume AN, Freitas RP, Goud B, Benaroch P, Hacohen N, Fukuda M, Desnos C, Seabra MC, Darchen F, Amigorena S, Moita LF, Thery C (2010) Rab27a and Rab27b control different steps of the exosome secretion pathway. Nat Cell Biol 12:19-30; sup 11-13. CrossRef Medline

Pankiv S, Alemu EA, Brech A, Bruun JA, Lamark T, Overvatn A, Bjørkøy G, Johansen T (2010) FYCO1 is a Rab7 effector that binds to LC3 and PI3P to mediate microtubule plus end-directed vesicle transport. J Cell Biol 188:253-269. CrossRef Medline

Peralta ER, Martin BC, Edinger AL (2010) Differential effects of TBC1D15 and mammalian Vps39 on Rab7 activation state, lysosomal morphology, and growth factor dependence. J Biol Chem 285:16814-16821. CrossRef Medline

Perrett RM, Alexopoulou Z, Tofaris GK (2015) The endosomal pathway in Parkinson's disease. Mol Cell Neurosci 66:21-28. CrossRef Medline

Pickrell AM, Youle RJ (2015) The roles of PINK1, parkin, and mitochon- 
drial fidelity in Parkinson's disease. Neuron 85:257-273. CrossRef Medline

Poole AC, Thomas RE, Yu S, Vincow ES, Pallanck L (2010) The mitochondrial fusion-promoting factor mitofusin is a substrate of the PINK1/parkin pathway. PLoS One 5:e10054. CrossRef Medline

Poteryaev D, Datta S, Ackema K, Zerial M, Spang A (2010) Identification of the switch in early-to-late endosome transition. Cell 141:497-508. CrossRef Medline

Rakovic A, Shurkewitsch K, Seibler P, Grünewald A, Zanon A, Hagenah J, Krainc D, Klein C (2013) Phosphatase and tensin homolog (PTEN)induced putative kinase 1 (PINK1)-dependent ubiquitination of endogenous Parkin attenuates mitophagy: study in human primary fibroblasts and induced pluripotent stem cell-derived neurons. J Biol Chem 288: 2223-2237. CrossRef Medline

Rojas R, van Vlijmen T, Mardones GA, Prabhu Y, Rojas AL, Mohammed S, Heck AJ, Raposo G, van der Sluijs P, Bonifacino JS (2008) Regulation of retromer recruitment to endosomes by sequential action of Rab5 and Rab7. J Cell Biol 183:513-526. CrossRef Medline

Romero Rosales K, Peralta ER, Guenther GG, Wong SY, Edinger AL (2009) Rab7 activation by growth factor withdrawal contributes to the induction of apoptosis. Mol Biol Cell 20:2831-2840. CrossRef Medline

Sarraf SA, Raman M, Guarani-Pereira V, Sowa ME, Huttlin EL, Gygi SP, Harper JW (2013) Landscape of the PARKIN-dependent ubiquitylome in response to mitochondrial depolarization. Nature 496:372-376. CrossRef Medline

Scott CC, Vacca F, Gruenberg J (2014) Endosome maturation, transport and functions. Semin Cell Dev Biol 31:2-10. CrossRef Medline

Seals DF, Eitzen G, Margolis N, Wickner WT, Price A (2000) A Ypt/Rab effector complex containing the Sec1 homolog Vps33p is required for homotypic vacuole fusion. Proc Natl Acad Sci U S A 97:9402-9407. CrossRef Medline

Seaman MN, Harbour ME, Tattersall D, Read E, Bright N (2009) Membrane recruitment of the cargo-selective retromer subcomplex is catalysed by the small GTPase Rab7 and inhibited by the Rab-GAP TBC1D5. J Cell Sci 122:2371-2382. CrossRef Medline
Small SA, Petsko GA (2015) Retromer in Alzheimer disease, Parkinson disease and other neurological disorders. Nat Rev Neurosci 16:126-132. CrossRef Medline

Spillantini MG, Schmidt ML, Lee VM, Trojanowski JQ, Jakes R, Goedert M (1997) Alpha-synuclein in Lewy bodies. Nature 388:839-840. CrossRef Medline

Tsunemi T, Hamada K, Krainc D (2014) ATP13A2/PARK9 regulates secretion of exosomes and alpha-synuclein. J Neurosci 34:15281-15287. CrossRef Medline

Vanlandingham PA, Ceresa BP (2009) Rab7 regulates late endocytic trafficking downstream of multivesicular body biogenesis and cargo sequestration. J Biol Chem 284:12110-12124. CrossRef Medline

Volpicelli-Daley LA, Gamble KL, Schultheiss CE, Riddle DM, West AB, Lee VM (2014) Formation of alpha-synuclein Lewy neurite-like aggregates in axons impedes the transport of distinct endosomes. Mol Biol Cell 25:4010-4023. CrossRef Medline

Wagner SA, Beli P, Weinert BT, Nielsen ML, Cox J, Mann M, Choudhary C (2011) A proteome-wide, quantitative survey of in vivo ubiquitylation sites reveals widespread regulatory roles. Mol Cell Proteomics 10: M111.013284. CrossRef Medline

Wang T, Hong W (2002) Interorganellar regulation of lysosome positioning by the Golgi apparatus through Rab34 interaction with Rabinteracting lysosomal protein. Mol Biol Cell 13:4317-4332. CrossRef Medline

Wurmser AE, Sato TK, Emr SD (2000) New component of the vacuolar class C-Vps complex couples nucleotide exchange on the Ypt7 GTPase to SNARE-dependent docking and fusion. J Cell Biol 151:551-562. CrossRef Medline

Yamano K, Fogel AI, Wang C, van der Bliek AM, Youle RJ (2014) Mitochondrial Rab GAPs govern autophagosome biogenesis during mitophagy. eLife 3:e01612. CrossRef Medline

Yasuda T, Nakata Y, Mochizuki H (2013) alpha-Synuclein and neuronal cell death. Mol Neurobiol 47:466-483. CrossRef Medline 